\title{
The role of Self-efficacy, Time Perspective, and Conformity Pressure in Temptation for Smoking and Substance Use among University Students
}

\author{
Pegah Nejat ${ }^{1, *}$, Fatemeh Bagherian ${ }^{2}$
}

\footnotetext{
${ }^{1}$ Assistant Professor, Department of Education and Psychology, Shahid Beheshti University, Tehran, Iran

${ }^{2}$ Associate Professor, Department of Education and Psychology, Shahid Beheshti University, Tehran, Iran
}

\section{ARTICLE INFO}

\section{Article History}

Received: 27 April 2019

Revised: 10 November 2020

Accepted: 16 November 2020

Available online: February2021

Article Type

Research Article

Keywords

Time Perspective; Self-efficacy; Cigarette Smoking; Social Pressure; Substance Use Temptation

\section{Corresponding Author*}

Pegah Nejat received her Ph.D. in Psychology from Shahid Beheshti University. She is currently an Assistant Professor of Psychology at Shahid Beheshti University. Her research interests include moral psychology, self and intergroup processes, and cultural psychology. Correspondence concerning this article should be addressed to Pegah Nejat, Department of Psychology and Education, Shahid Beheshti University, Evin Ave., Tehran, Postal Code 1983969411.

ORCID: 0000-0003-1410-9720

E-mail: p_nejat@sbu.ac.ir

doi: http://dx.doi.org/10.29252/bjcp.14.2.26

\section{ABSTRACT}

Identifying factors which contribute to young adults' temptation for substance use is a significant step toward prevention of this social harm. The current study aimed to examine the role of a set of personal and social factors and their interaction in shaping temptation for cigarette smoking and substance use among university students.

Participants were 766 students at Shahid Beheshti University who responded to self-efficacy and time perspective measures, as well as questions concerning popularity among family and friends, temptation for smoking/substance use, and social pressure. Hierarchical regression analysis was performed to determine predictors of temptation for substance use and smoking. In the first step, demographic variables, in the second step, self-efficacy, time perspective, social popularity, and social pressure, and in the third step the interaction of social pressure with the other predictors were entered.

Religiosity, present hedonism, popularity among family, and social pressure predicted temptation for smoking cigarettes. Further, substance temptation was determined by parents' marital status, religiosity, self-efficacy, social pressure, and the interaction of social pressure with either of the variables gender, perceived morality, self-efficacy, futurism, and present fatalism. As revealed by interactive effects, the effect of social pressure was stronger for men and individuals lower in either selfefficacy, perceived morality, futurism, or present fatalism.

Despite the noticeable role of social pressure in shaping temptation for substance use, this effect was moderated by selfefficacy, perceived morality, and time perspective. Therefore, designing interventions targeting these moderators can reduce the harm caused by social pressure.

Citation: Nejat, P., \& Bagherian, F. (1399/2021). The role of Self-efficacy, Time Perspective, and Conformity Pressure in Temptation for Smoking and Substance Use among University Students. Contemporary Psychology, 14(2), 26-37. http://dx.doi.org/10.29252/bjcp.14.2.26 


\title{
نقش خودكار آمدى، جشمانداز زمان و فشار همرنكى در كرايش به سوءمصرف مواد و سيكار كشيدن در دانشجويان
}

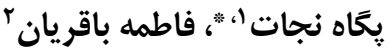

\author{
' ' استاديار كروه روانشناسى، دانشكاه شهييد بهشتى، تهران، ايران

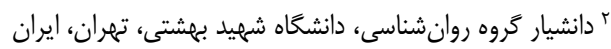

اطلاعات مقاله

\begin{abstract}
جكيده

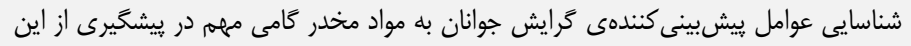

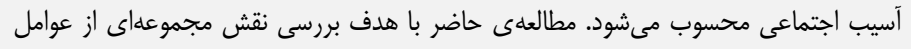

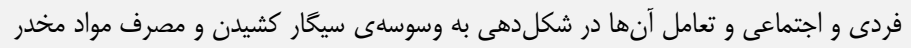
در ميان دانشجويان انجام شد.

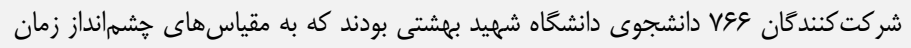

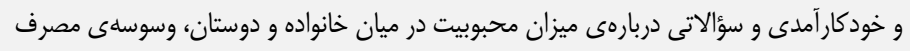

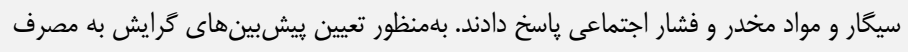

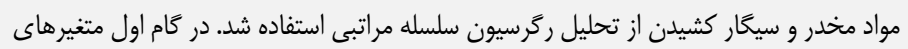

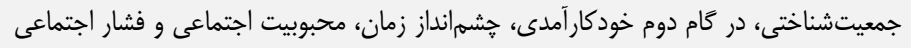

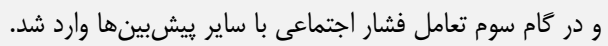

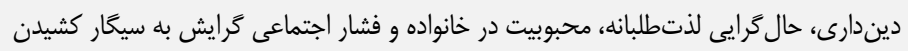

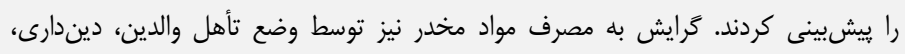

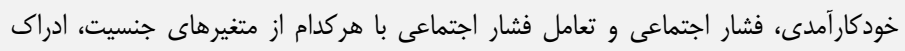

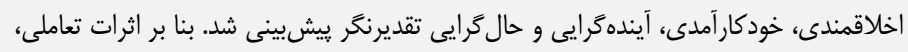

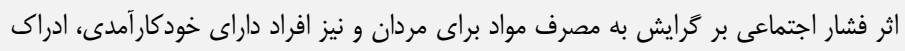

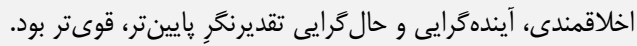

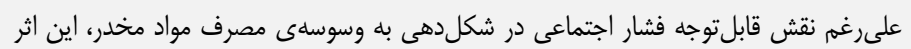

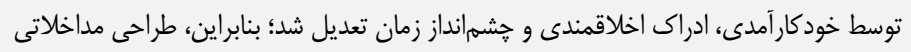

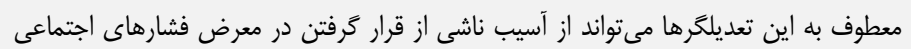

بكاهد.

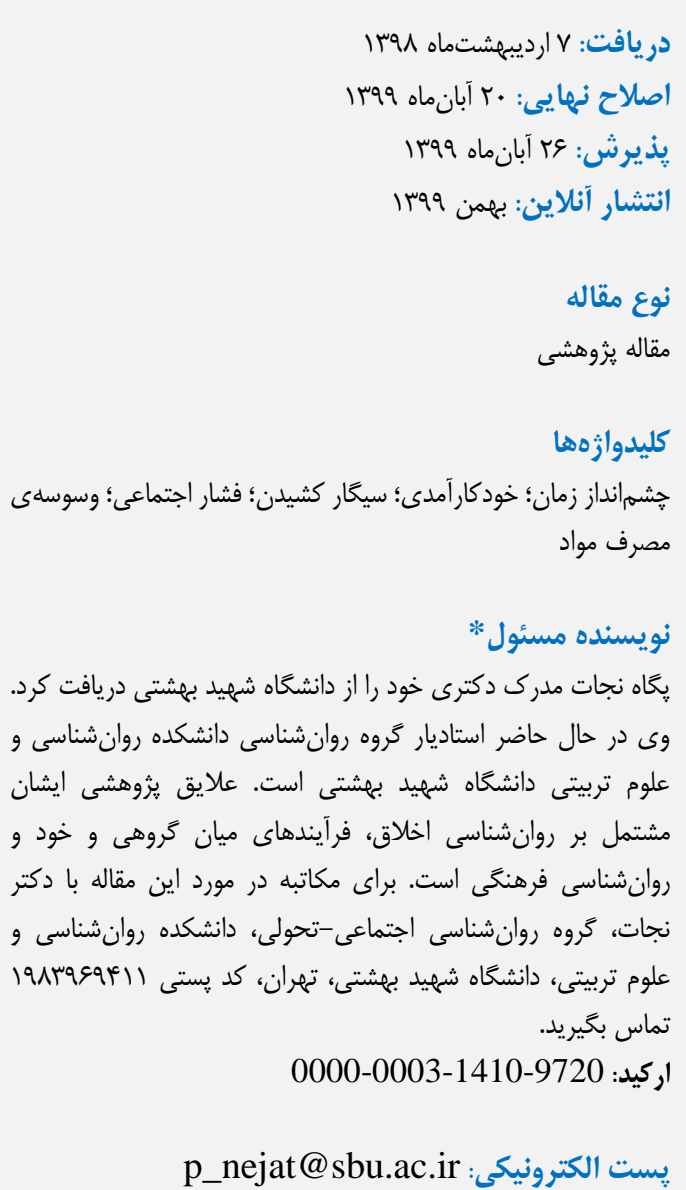

pست الكترونيكى: p_nejat@sbu.ac.ir

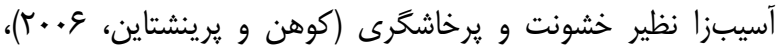

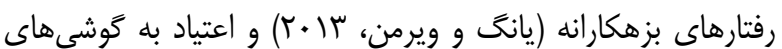

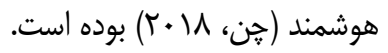

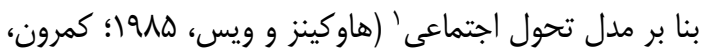

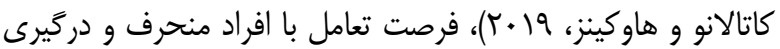
در فعاليتهاى منحرف نقش تعيين كنندهاى در ييشرفت فرد در مسير مبادرت به رفتارهاى منحرف اجتماعى ازجمله مصرف مواد (ايرانيور، جمشيدى، نخعى، حقدوست، شجاعى زاده، افتخار اردبيلى و افتخار

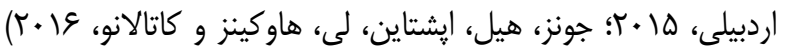
دارد و واسط اين اثر دريافت تقويت بابت انجام اين رفتارها از سوى هين،
انديشمندان علوم رفتارى اجتماعى از ديرباز دغدغهى مشكلات

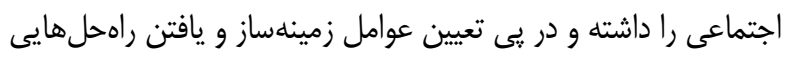

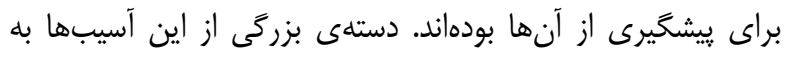

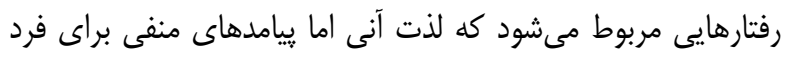

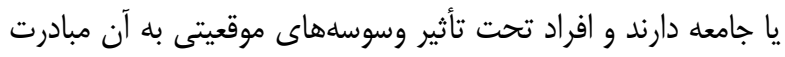

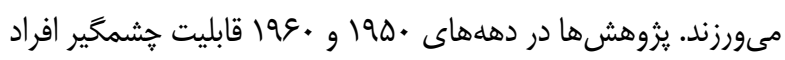

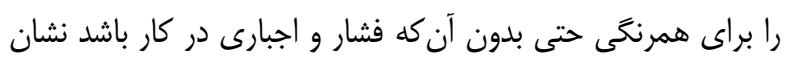

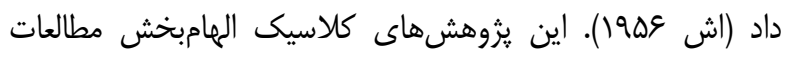

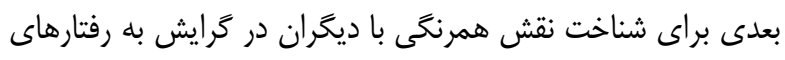


كه منبع انخَيزش و قصد رفتار و انتخاب اهداف و تعهد به آنها

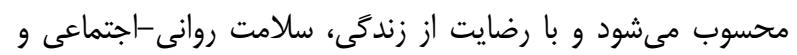

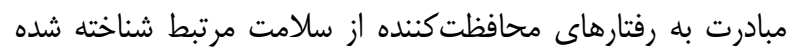

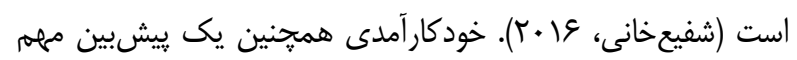

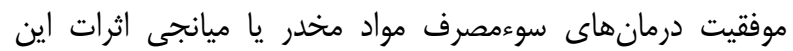

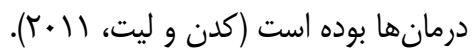

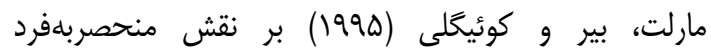

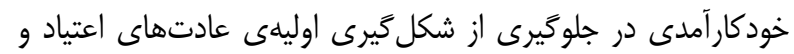

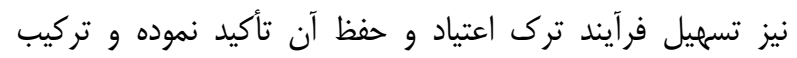

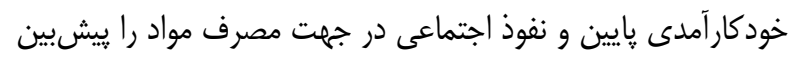

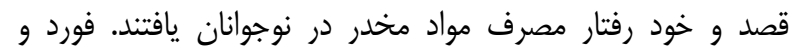

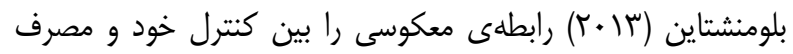

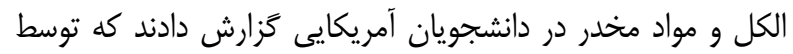

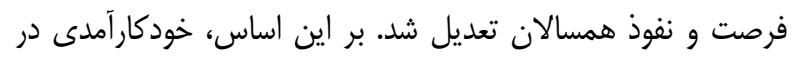
جارجوب يزوهش حاضر بلهنوان عاملى حفاظت كننده در نظر گرفته

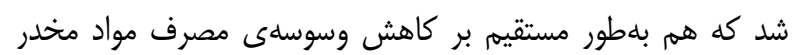

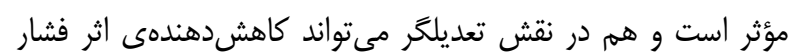

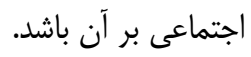

خودتنظيمگرى ارتباط تنگاتنكى با توانايى مجسم نمودن

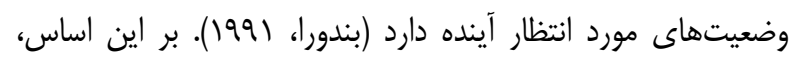

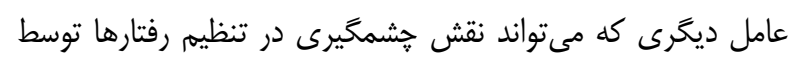

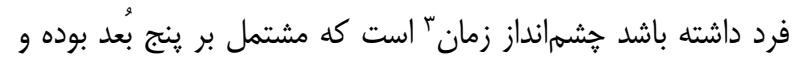

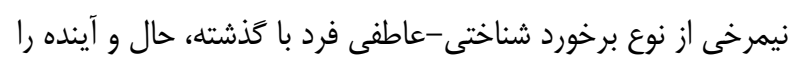

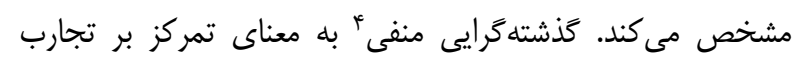

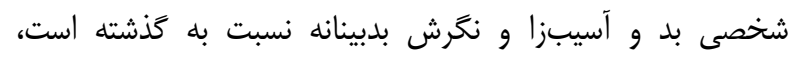

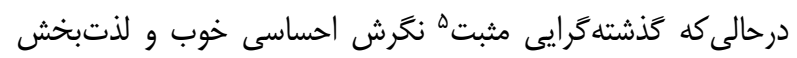
نسبت به وقايع كذشته و دلتنگى براى روابط صميمانه با خانواده و

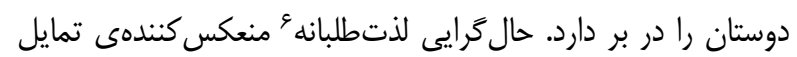

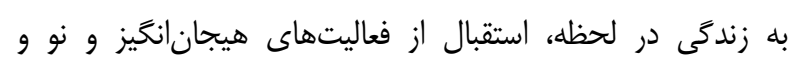

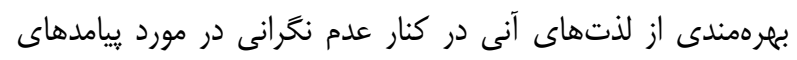

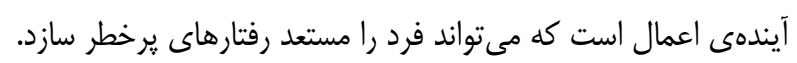

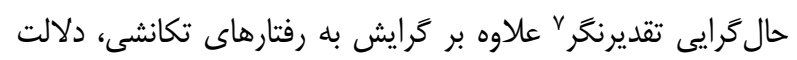

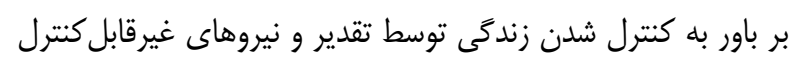

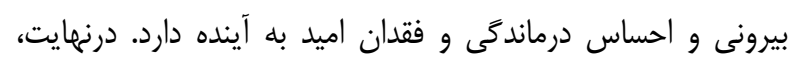

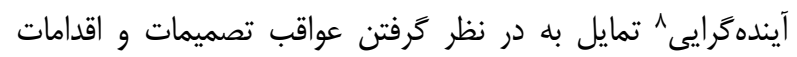

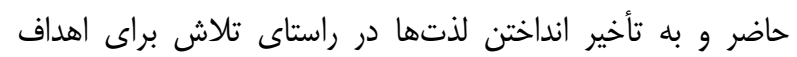

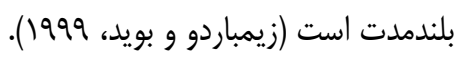

كذشتهرا ايى منفى و حال

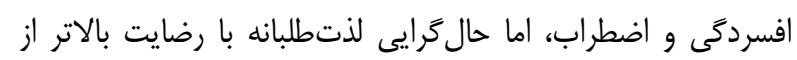

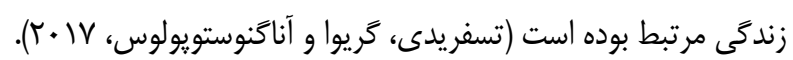

ديگران، بخصوص خانواده و همسالان است. در اين راستا انتظار

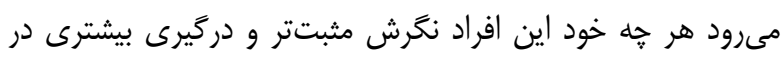

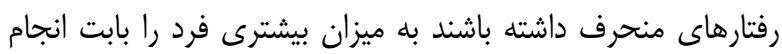

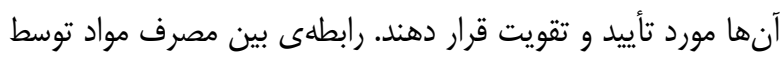

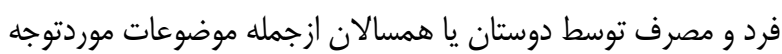

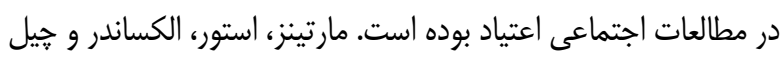

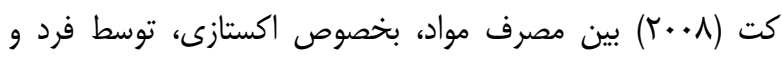
دوستان نزديك وى رابطه يافتند. در مطالعهاى ديخر، ادراى از ميزان

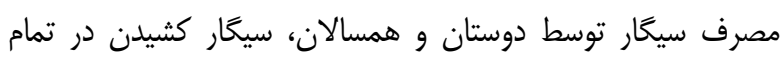
طول نوجوانى را ييشبينى كرد، درحالى كه اين اثر در مورد الكل و مارى جوانا ازنظر زمانى محدودتر بود. در تبيين آن، نويسندكان احتمال

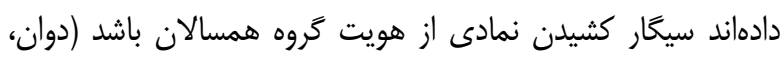

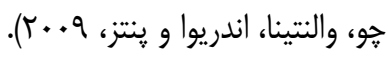

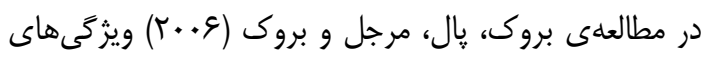

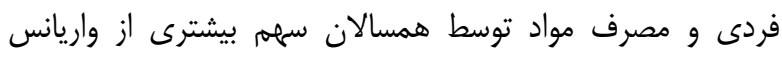
مصرف مواد را نسبت به عوامل والدى و تنشززاهاى محيطى تبيين

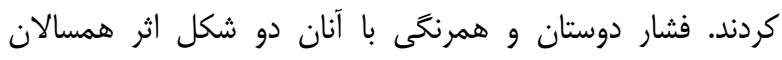

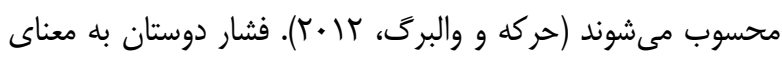

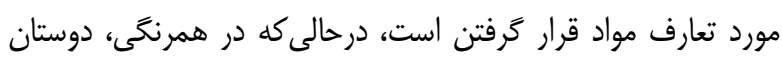

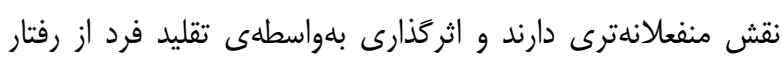

$$
\text { مصرف همسالان صورت مى گيرد. }
$$

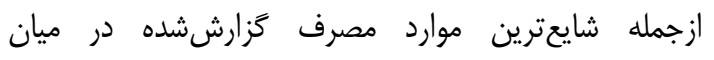

دانشجويان ايرانى سيخار، الكل و قليان هستند (سفيرى، رحيمى موقر،

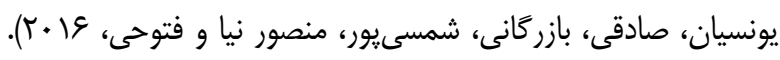

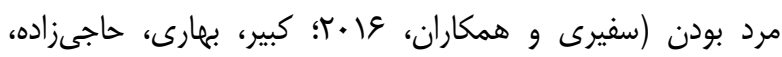

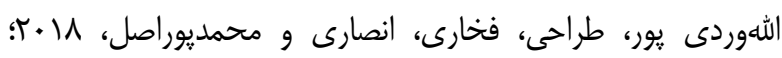

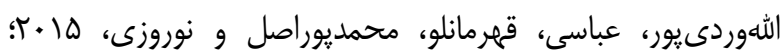

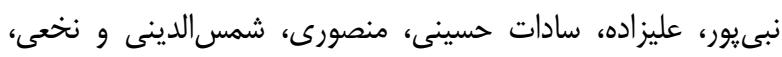

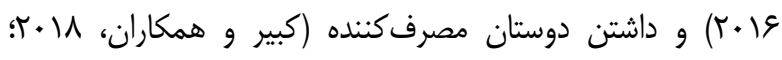

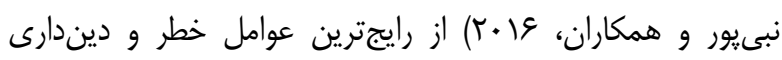

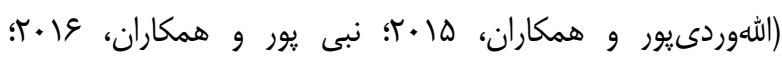

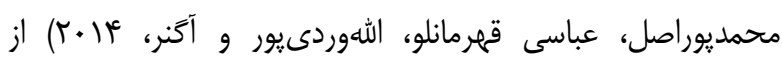
رايجترين عوامل محافظت كننده در اين مطالعات كزارش شدهاند.

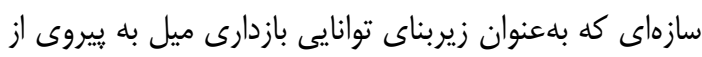

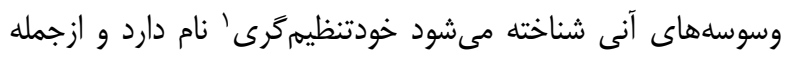

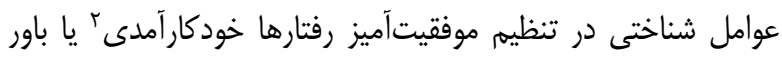

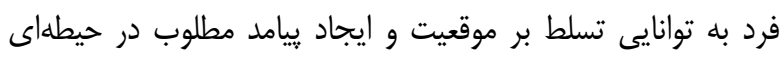

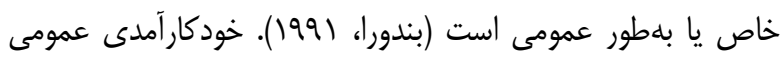

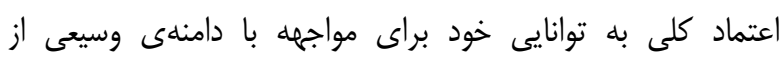

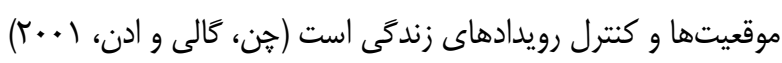

\footnotetext{
${ }^{5}$ past positive

${ }^{6}$ present hedonistic

${ }^{7}$ present fatalistic

${ }^{8}$ future
}

\footnotetext{
${ }^{1}$ self-regulation

2 self-efficacy

${ }^{3}$ time perspective

${ }^{4}$ past negative
} 
مورد يذيرش بودن در ميان خانواده و دوستان نقش محافظت كنندهاى

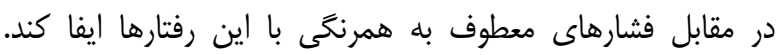

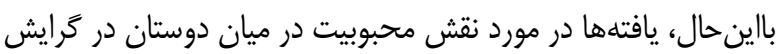
به مصرف مواد و ساير رفتارهاى منحرف اجتماعى يكدست نيست و دئن

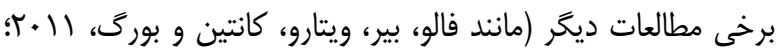

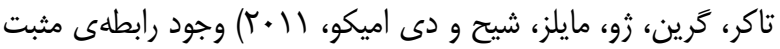

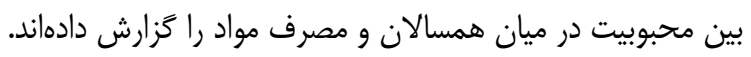

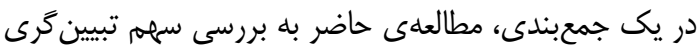

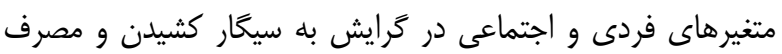

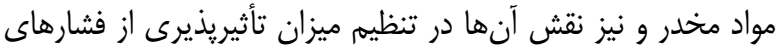
اجتماعى در جهت مصرف مواد مىيردازد. در اين راستا، باور بهانه

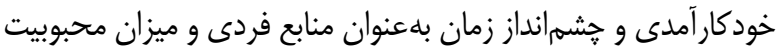

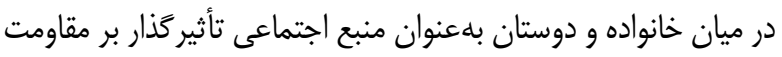

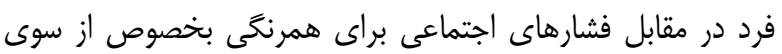

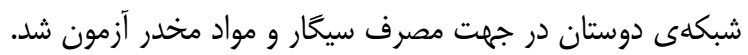

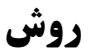

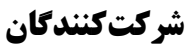

شركتكنندان V99 نفر دانشجوى مشغول به تحصيل در

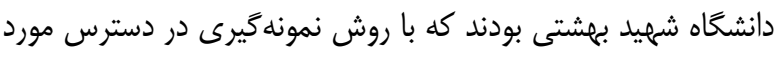

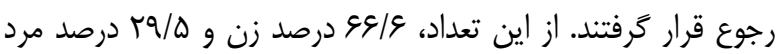

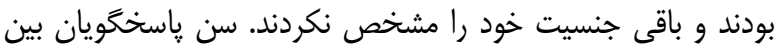

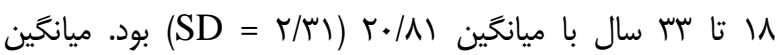

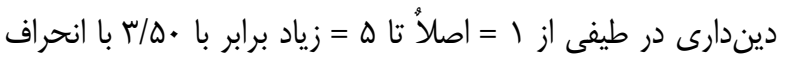

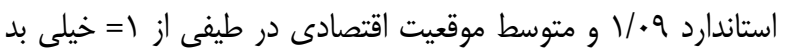

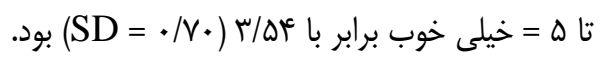

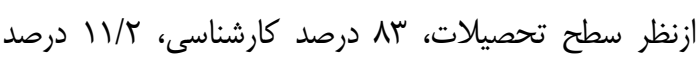

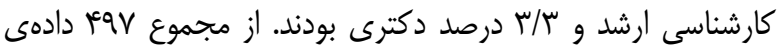

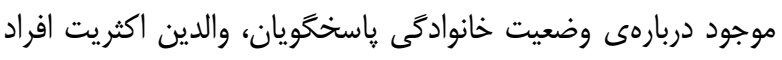

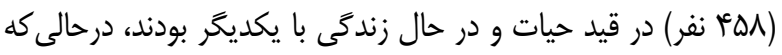

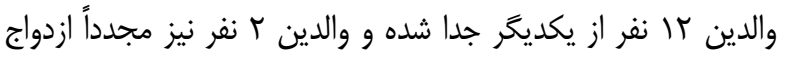

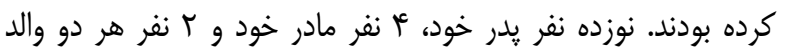

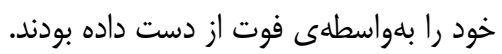

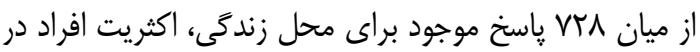

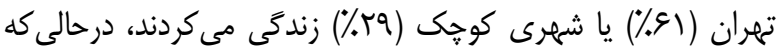

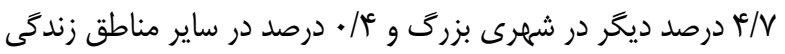

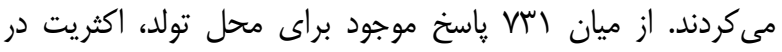

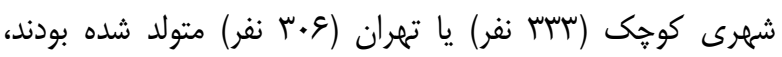

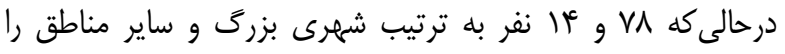

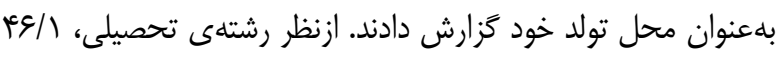

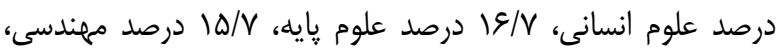

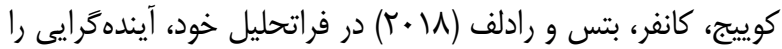

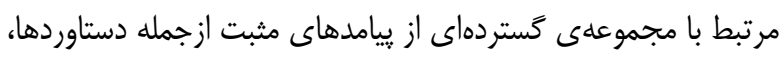

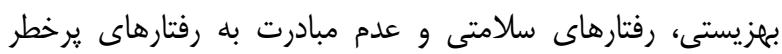
يافتند، بخصوص كه قدرت ييشيينى

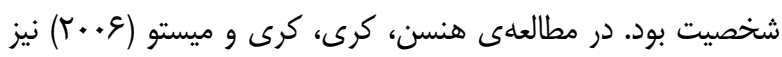

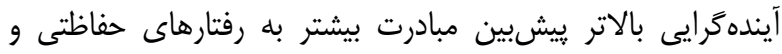

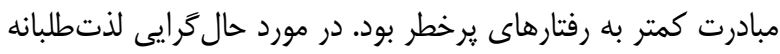
الكوى معكوس اما قوىترى از ارتباط با رفتارهاى مذكور مشاهده شدادي.

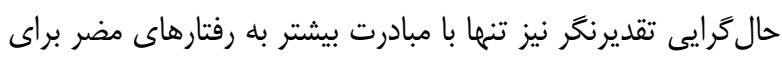

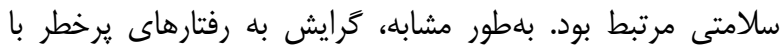

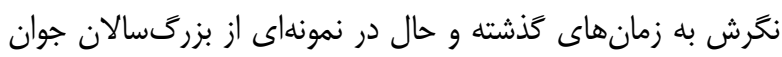

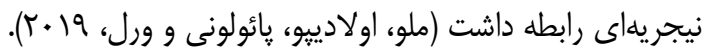
سعهم منحصربهفرد حال

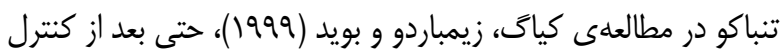

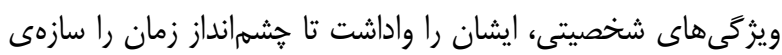

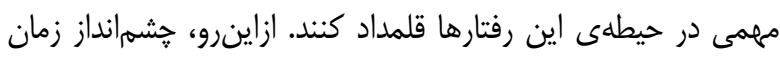

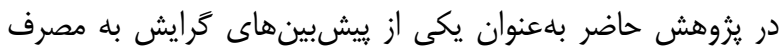

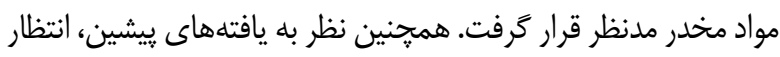

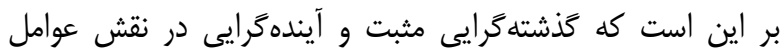

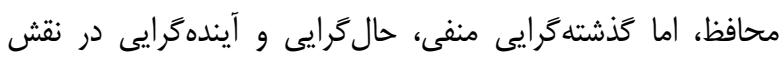

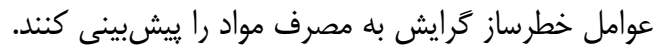

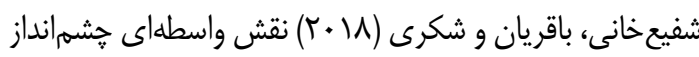

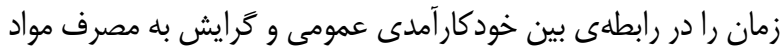

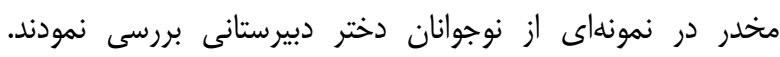

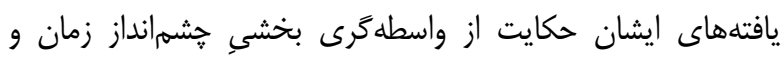

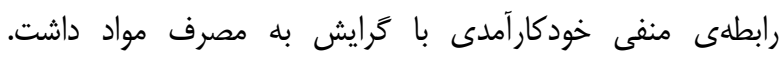

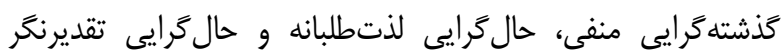

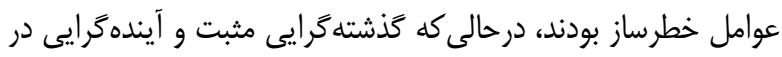

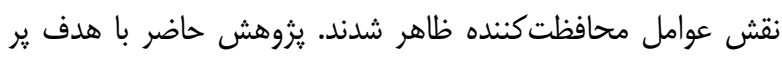

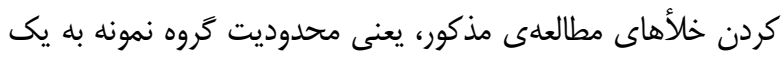

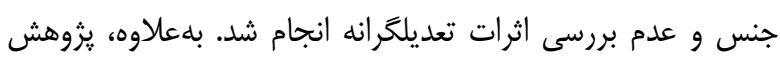

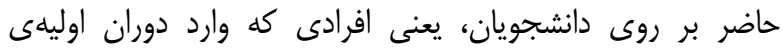

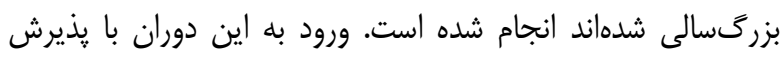

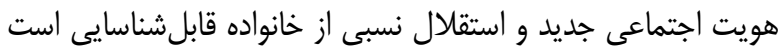

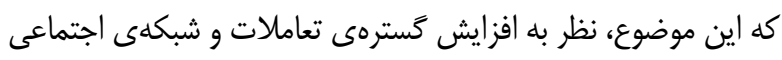

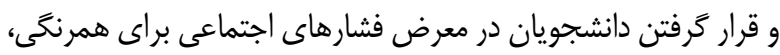
تهديدات بالقوهاى را متوجه آنان مى كند.

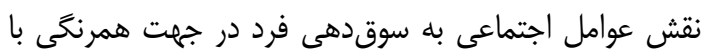

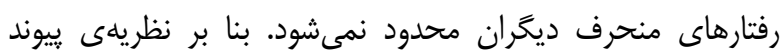

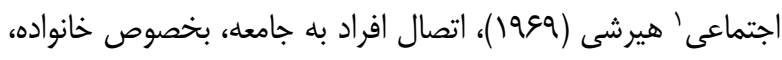

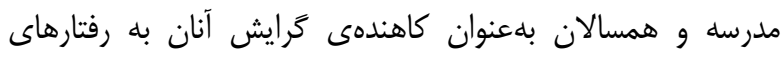

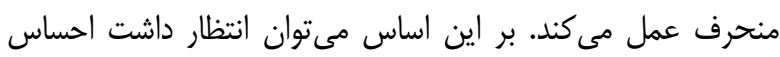


تحصيلات، رشتهى تحصيلى، وضع تأهل والدين، شهر محل تولد و

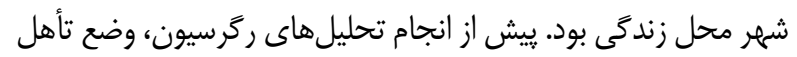

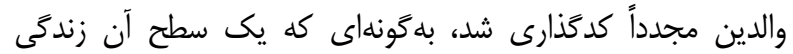

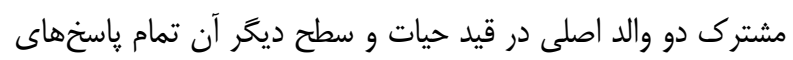
ممكن ديخر (طلاق، ازدواج مجدد، فوت) رات رات شامل شد.

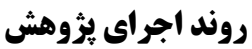

يرسشنامهها بلصورت كاغذى در اختيار پاسخكَويان قرار كرفت

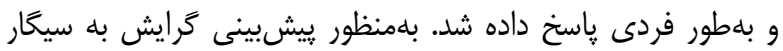
كشيدن توسط عوامل فردى و اجتماعى از يك ركَرسيون سلسله

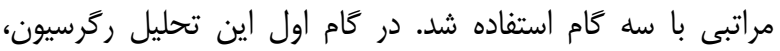

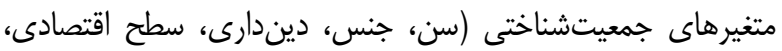

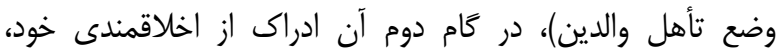

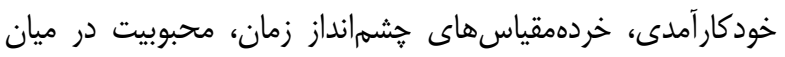

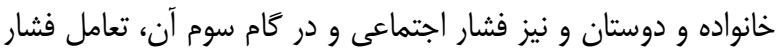

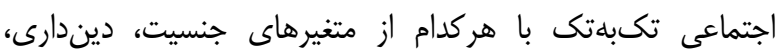

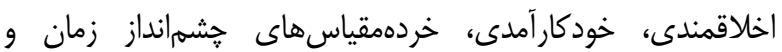
محبوبيت در ميان خانواده و دوستان وارد شد.

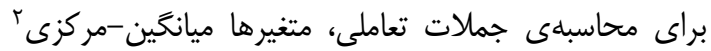

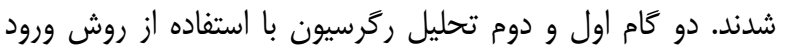

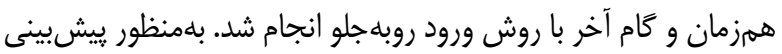
كرايش به مصرف مواد مخدر، تحليل ركَرسيونى با متغيرهاى بيشبين

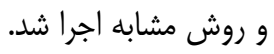

\section{نتايج}

جدول I ميانگين، انحراف استاندارد و ضرايب همبستىى

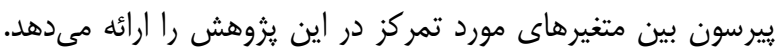

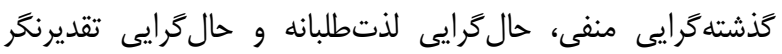

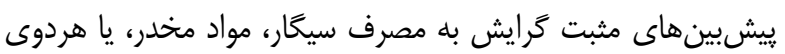

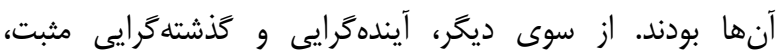
خودكارآمدى، ادراك از اخلاقمندى خود و محبوبيت إنيت ميان خانوادها

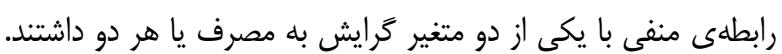

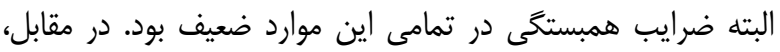

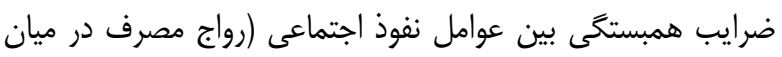

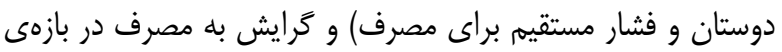

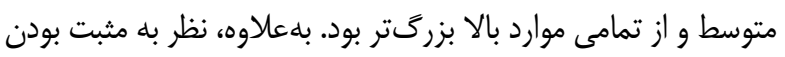

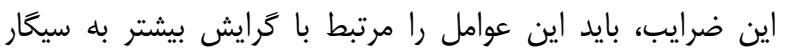
كشيدن و مصرف مواد مخدر محسوب نمود. مطابق جدول (، همبستكى بين محبوبيت در ميان خانواده و

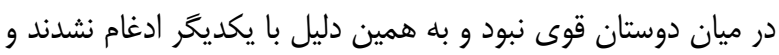
در تحليلها متغيرهايى جداكانه باقى ماندند. ازآنجاكه همبستخى بين دين دئن كرايش به سيكار كشيدن و كرايش به مصرف مواد مخدر، بيـن رواج

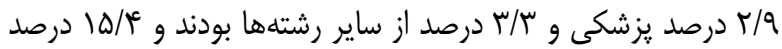

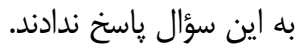

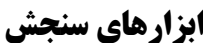

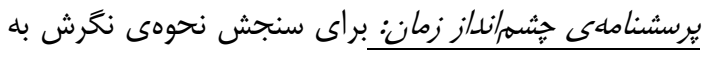

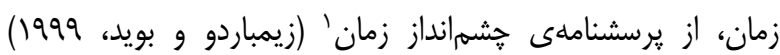

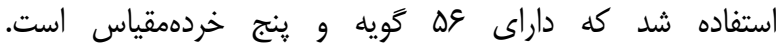

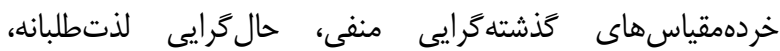

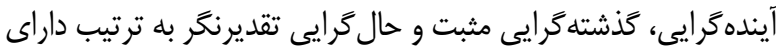

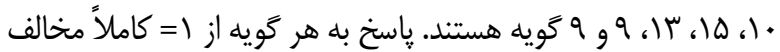
تا هـ = كاملاً موافق متغير بود.

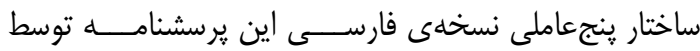

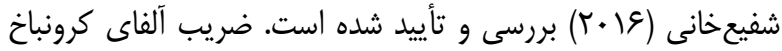

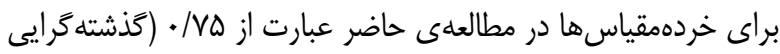

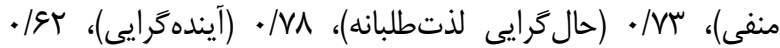

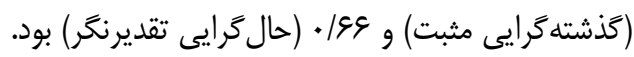

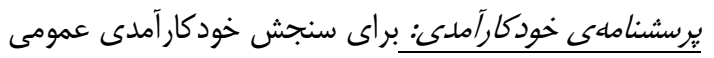

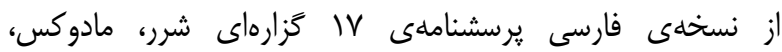

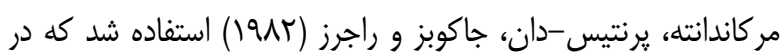

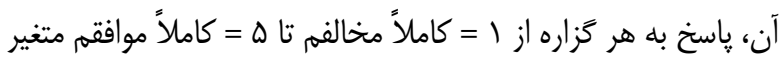

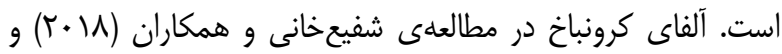

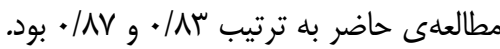

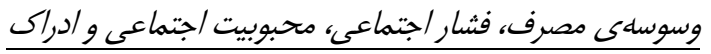
از اخلاقمندى: هشت يرسش بلمنظورار سنجش وسوساهى مصرف،

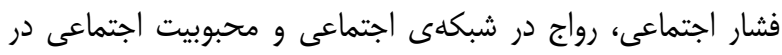

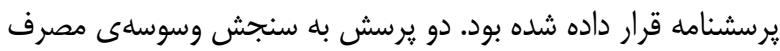

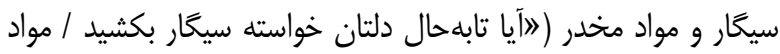
مخدر مصرف كنيد؟《) اختصاص داشت. دو يرسش ديخر مربوط بهان

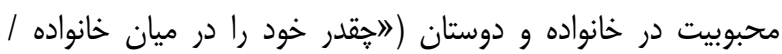
دوستان محبوب مىدانيد؟)) بود. دو يرسش ديكر نيز به سنجش ردان رواج مصرف سيخار (اآيا دوستان نزديك شما سيخار مى كشند؟ی)) و ورواج

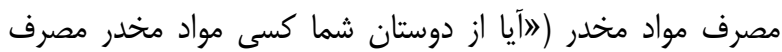
مى كند؟) در ميان دوستان فرد يرداخت. ميزان قرار كَفتن در معرض فشار اجتماعى مستقيم براى درداى

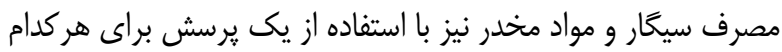

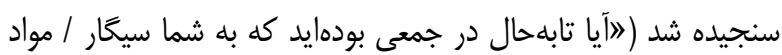

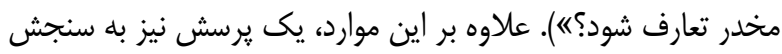

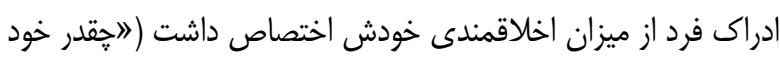

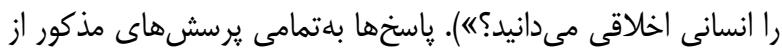
1

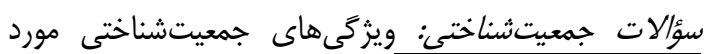
سؤال عبارت از سن، جنس، موقعيت اقتصادى، سطح ديندارى، سطح 
جدول (. ميانكَين، انحراف استاندارد و ضرايب همبستخى بين متغيرهاى كرايش به مصرف، عوامل فردى و عوامل اجتماعى

\begin{tabular}{|c|c|c|c|c|c|c|c|c|c|}
\hline انحراف استاندارد & ميانگين & & & & & & r & 1 & 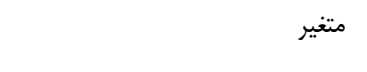 \\
\hline $1 / 41$ & $T / I Q$ & & & & & & & - & 1. كَرايش به سيكار كشيدن \\
\hline.$/ 90$ & $1 / 49$ & & & & & & - &.$/ 01$ & r. ترايش به مصرف مواد مخدر \\
\hline.$/ 94$ & $r / \cdot r$ & & & & & - & $.1 \cdot 4$ & $\cdot 1 \cdot 1$ & "ا. كَذشته كرايى منفى \\
\hline.$/ \Delta F$ & $r / r q$ & & & & - & $\cdot|r|$ & $.1 \cdot 1$ & $\cdot|r|$ & f. حال كرايى لذتطلبانه \\
\hline . & $r / \mu r$ & & & - &.$/ 11$ & .1 .4 &.$- / 10$ &.$- / 10$ & هـ آيندهر ايى \\
\hline .109 & $r / T \Lambda$ & & - &.$/ 41$ & 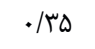 & $-\cdot 1 \cdot \Delta$ &.$- / 11$ & $-\cdot 1 \cdot e^{c}$ & و. كذشته \\
\hline.$|9|$ & $r / V \pi$ & - & $-\cdot / \mathrm{VV}$ & $-\cdot / r v$ & $.1 \cdot v$ & 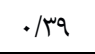 & 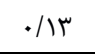 & .111 & V. حال كرايى تقدير نحر \\
\hline$\cdot / \Delta V$ & r/qr & & & & & &.$- / 11$ &.$- / 1 r$ & ي. خودكار آمدى \\
\hline .199 & $F / \mu 1$ & & & & & & $-\cdot / 11$ &.$- / 14$ & 9. ادراى از اخلاقمندى خود \\
\hline$\cdot / \mathrm{NF}^{\mathrm{C}}$ & $F / \Delta I$ & & & & & - &.$- / 10$ &.$- / 11$ & •. 1. محبوبيت ميان خانواده \\
\hline$\cdot 180$ & $r / \mu 1$ & & & & - & .148 & -.1 .9 & $.1 \cdot 1$ & 11. محبوبيت ميان دوستان \\
\hline 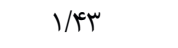 & $r / \pi$ & & & - & $\cdot 1 \cdot V$ &.$- / 11$ & 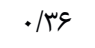 &.$/ \Delta F$ & ז1. رواج سيخار كشيدن در دوستان \\
\hline $1 / \cdot 1$ & I/QT & & - & $\cdot / \Delta \Delta$ & $-\cdot / \cdot 1$ &.$- / 14$ & .19 & 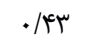 & سا. رواج مصرف مواد در دوستان \\
\hline $1 / 0$. & $T / T \Lambda$ & - & .10 &.$/ W V$ & .1 .9 & $-\cdot 1 \cdot 1$ & 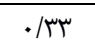 & .19. & fi. فشار مستقيم براى سيكار كشيدن \\
\hline .19. & $1 / r 4$ &.$/ 48$ & $\cdot / \mathrm{N}^{c}$ &.$/ 4 \mathrm{~V}$ &.$- / . e^{c}$ &.$- / 14$ & .108 & 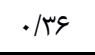 & ها. فشار مستقيم براى مصرف مواد \\
\hline
\end{tabular}

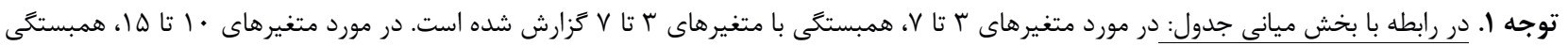

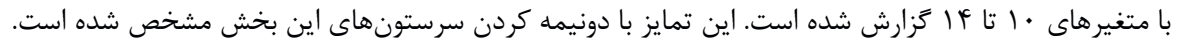

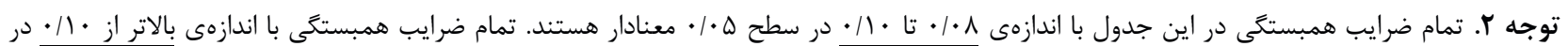

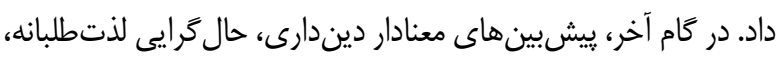

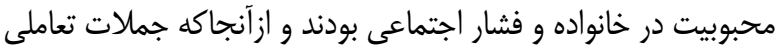

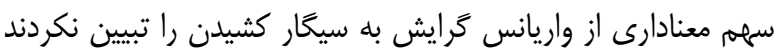
در مدل نهايى در زمرهى متغيرهاى ييشبين قرار نغر فتند.

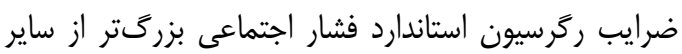

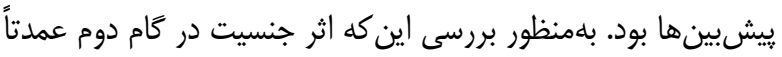

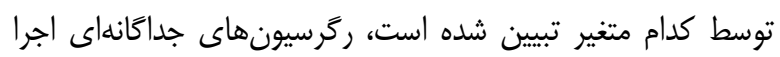

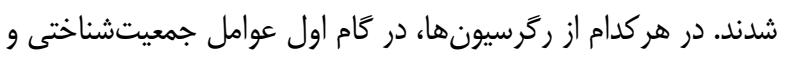

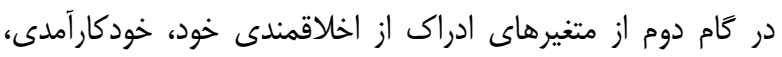

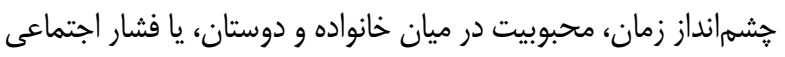

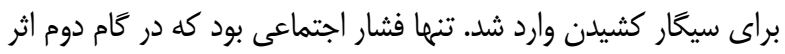

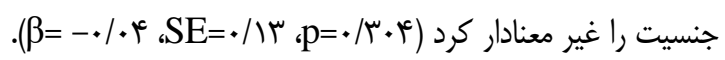
اجراى آزمونهاى t مستقل مقايسهى دو جنس درد ويثگى هاى روانشناختى فردى و فشار اجتماعى نشان داد تفاوت أنسات

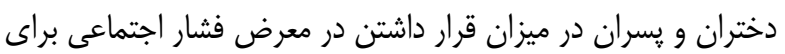

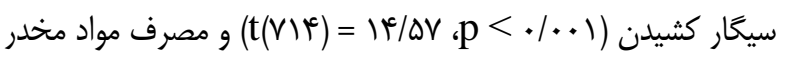

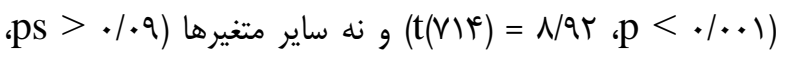

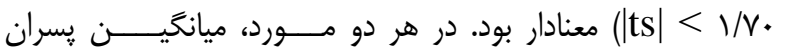

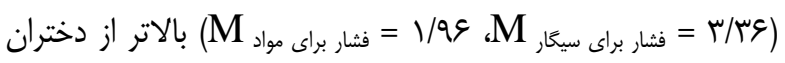

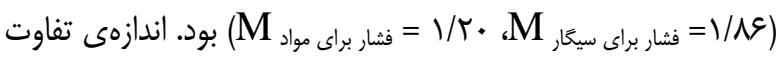

اين دو در دوستان و نيز بين فشار اجتماعى مستقيم براى مصرف اين

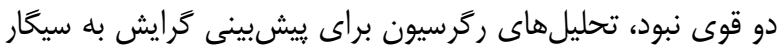

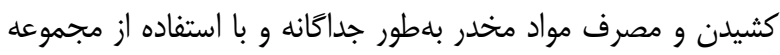
متغيرهاى متناظر با هر كدام در هر تحليل انجام شد.

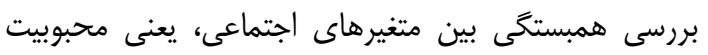

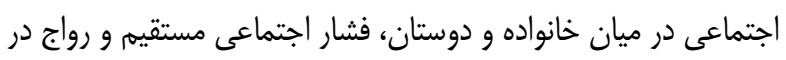

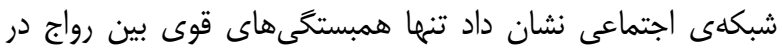

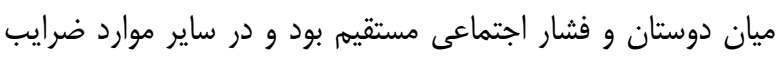

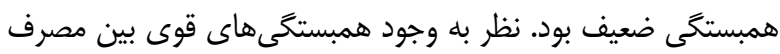

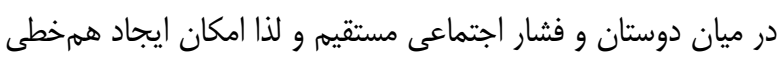

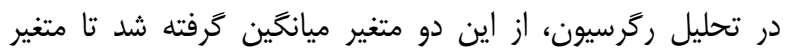

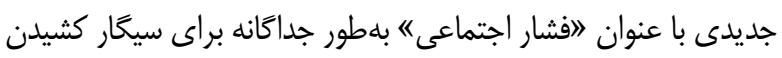
( $\alpha=$ و مصرف مواد مخدر (AV)

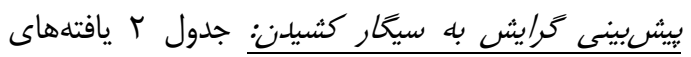

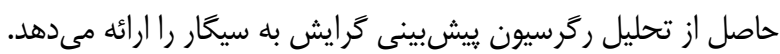

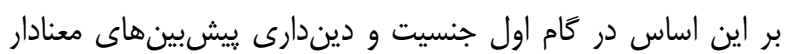

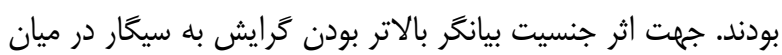

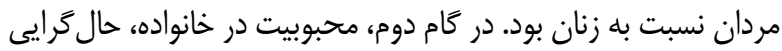

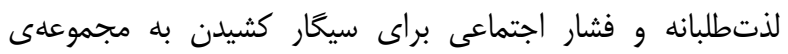
ييشيينهاى معنادار اضافه شد اما جنسيت معنادارى خود را از دست 


\begin{tabular}{|c|c|c|c|c|}
\hline \multicolumn{2}{|c|}{ كام دوم } & \multicolumn{2}{|c|}{ كام اول } & \multirow{2}{*}{ متغير ييشبين } \\
\hline خطاى استاندارد & ضريب استاندارد بتا & خطاى استاندارد & ضريب استاندارد بتا & \\
\hline.$/ \cdot r$ &.$- / \cdot r$ & $.1 \cdot r$ &.$- / . r$ & سن \\
\hline 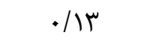 & $-\cdot / \cdot r$ & 童 & 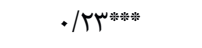 & جنس \\
\hline .119 & $.1 \cdot r$ & . & $.1 \cdot r$ & وضع تأهل والدين (دوطبقهاى) \\
\hline $.1 \cdot 0$ & $-\cdot / 1 Q^{* * * * * *}$ & $\cdot 1 \cdot 0$ & $-\cdot / \Gamma Y^{\text {*w* }}$ & ديندارى \\
\hline$\cdot 1 \cdot v$ & .1 .1 & $.1 \cdot 1$ & $.1 \cdot 0$ & سطح اقتصادى \\
\hline $.1 \cdot 1$ & $-.1 \cdot 4$ & & & ادراك از اخلاقمندى خود \\
\hline.$/$ & $-.1 \cdot 0$ & & & خودكار آمدى \\
\hline .1 .9 &.$/ . r$ & & & كذشتهر ايى منفى \\
\hline.$/ 11$ & $\cdot 1 \cdot \Lambda^{*}$ & & & حال گر ايى لذت طلبانه \\
\hline .11 & $-\cdot / \cdot r$ & & & آيندهرًايى \\
\hline .11 & .1 .4 & & & كذشتهاكر ايى مثبت \\
\hline .11 & $\cdot 1 \cdot 1$ & & & حال \\
\hline$\cdot 1 \cdot 1$ & 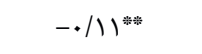 & & & محبوبيت در ميان خانواده \\
\hline .1 .9 & $\cdot / \cdot r$ & & & محبوبيت در ميان دوستان \\
\hline \multirow[t]{2}{*}{$.1 \cdot 0$} & 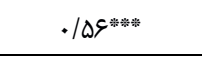 & & & فشار اجتماعى براى سيعار كشيدن \\
\hline & 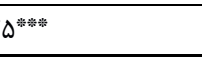 & & 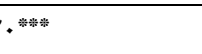 & Rغيير مجذور R \\
\hline
\end{tabular}

خانواده و دوستان، يا فشار اجتماعى براى مصرف مواد مخدر وارد شد.

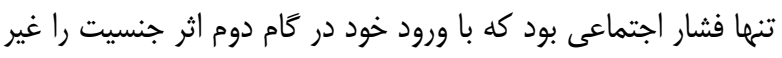

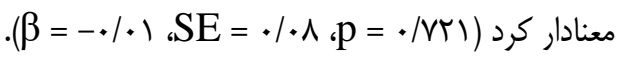
براى بيخيرى اثر تعاملى معنادار شدهى جنسيت در رابطهى بين في فشار

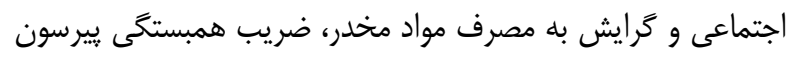

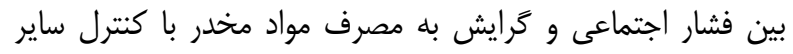

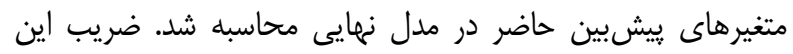

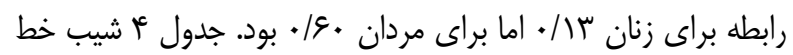

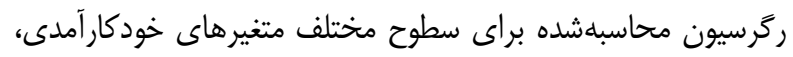

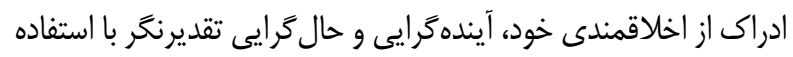

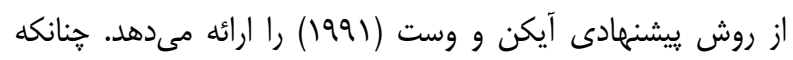

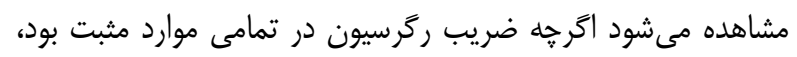

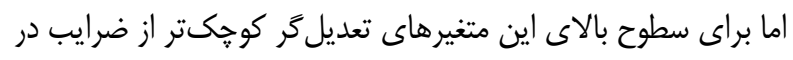

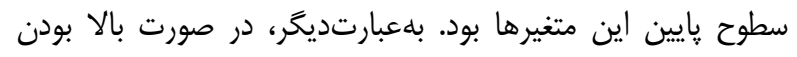

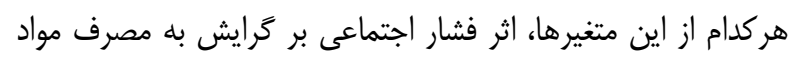
مخدر با كاهش همراه بود.

\section{بحث و نتيجه}

ازآنجاكه دانشجويان ادارهكندكان آيندهى جامعه هستند، براى داشتن

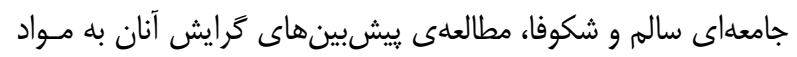

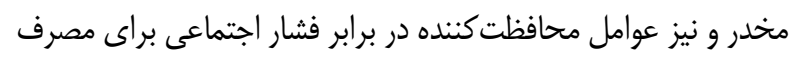
اين مواد از منظر روانشناسى اجتماعى حائز اهميت است. در اين راستا،

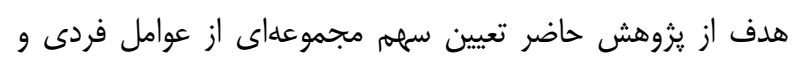

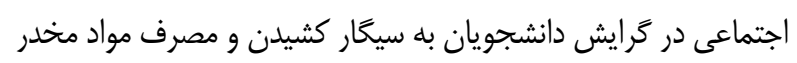

بين فشار اجتماعى براى سيكار كشيدن و مصرف مواد مخدر در پِّران

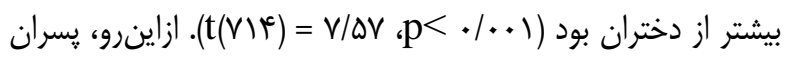

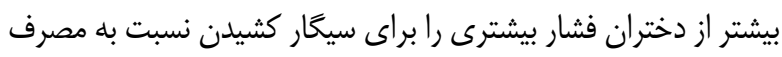
مواد مخدر تجربه مى كنند.

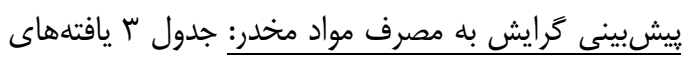

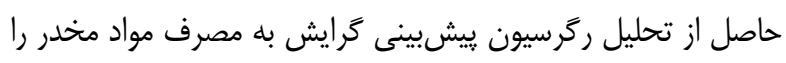

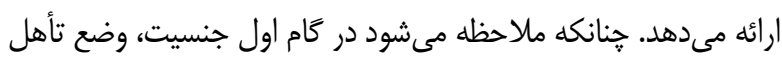

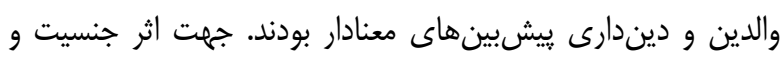

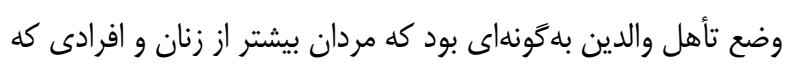

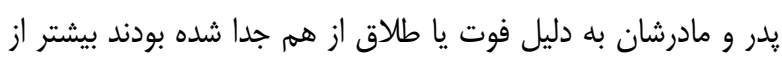

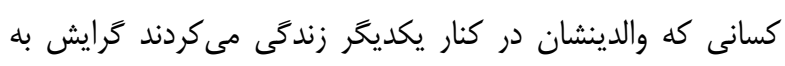

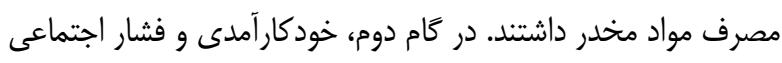

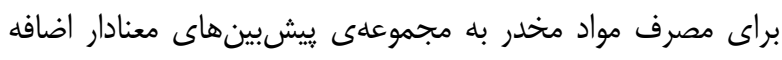

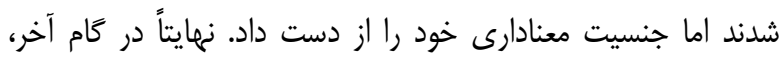

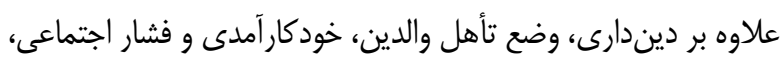

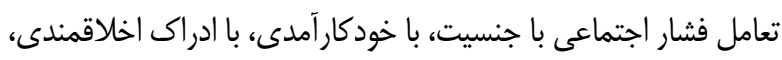

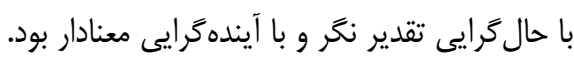

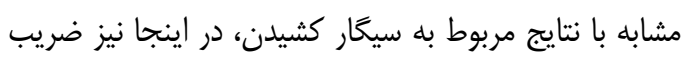

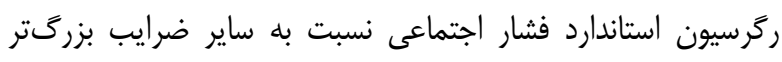

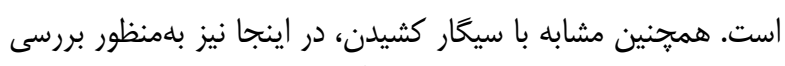

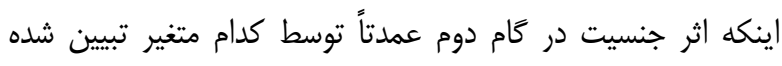

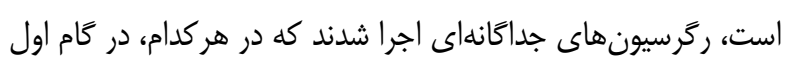

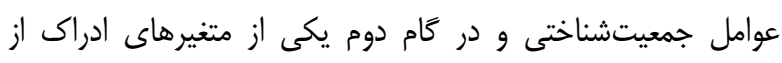

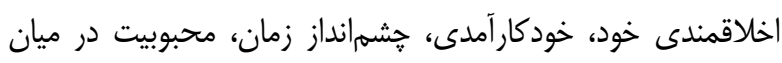


جدول س. نتايج تحليل رگر سيون ييشبينى گر ايش به مصرف مواد مخدر

\begin{tabular}{|c|c|c|c|c|c|c|}
\hline \multicolumn{2}{|c|}{ كَام آخر } & \multicolumn{2}{|c|}{ كام دوم } & \multicolumn{2}{|c|}{ كام اول } & \multirow{2}{*}{ متغير يِيشبين } \\
\hline خطاى استاندارد & بتا & خطاى استاندارد & بتا & خطاى استاندارد & بتا & \\
\hline $.1 \cdot 1$ &.$- .1 \cdot 1$ & .1 .1 & $-\cdot / \cdot r$ & $.1 \cdot r$ &.$- / \cdot r$ & سن \\
\hline$\cdot 1 \cdot v$ & $.1 \cdot 1$ & $.1 \cdot 1$ &.$- \cdot 1 \cdot 1$ & .1 .9 & 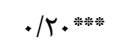 & 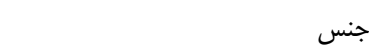 \\
\hline.$/ 1 r$ & $.1 .9 *$ &.$/ 14$ & $.1 \cdot 9^{*}$ & .110 & $\cdot 11 \cdot *$ & وضع تأهل والدين (دوطبقهاى) \\
\hline$\cdot 1 \cdot r$ & $-\cdot 1 \cdot \Lambda^{*}$ &.$/ \cdot r$ &.- .1 .9 & $.1 \cdot 4$ & $-\cdot / Y)^{* * * * *}$ & ديندارى \\
\hline$\cdot 1 \cdot 0$ &.$- .1 \cdot 1$ & $.1 \cdot 0$ &..$- / \cdot 1$ & .1 .9 &. & سطح اقتصادى \\
\hline $.1 \cdot 0$ & $.1 \cdot 1$ & $.1 \cdot 0$ &.$- / \cdot r$ & & & ادراك از اخلاقمندى خود \\
\hline .1 .9 & $-\cdot / 1 \cdot *$ & $\cdot / \cdot V$ & $-\cdot / \cdot *$ & & & خودكار آمدى \\
\hline .1 .9 & $-\cdot / \cdot r$ & .1 .9 & -.1 .9 & & & كذشتهَرًا ايى منفى \\
\hline$\cdot 1 \cdot v$ & $.1 \cdot 4$ & $\cdot / \cdot v$ &.$/ . r$ & & & حال رَر ايى لذتطلبانه \\
\hline .1 .9 & $-\cdot / \cdot 1$ & .1 .9 &.$- \cdot 1 \cdot f^{f}$ & & & آيندهَرايى \\
\hline .1 .9 &.$- \cdot \cdot 4$ & $\cdot / \cdot v$ & $-\cdot / \cdot r$ & & & كذشتهُرًا ايى مثبت \\
\hline .1 .9 &.$- \cdot 1 \cdot 4$ & .1 .9 & $-\cdot \cdot \cdot 1$ & & & حالخرايى تقديرنغر \\
\hline$\cdot 1 \cdot 0$ & $-.1 \cdot 0$ & $.1 \cdot 0$ & $-\cdot \cdot \cdot r$ & & & محبوبيت در ميان خانواده \\
\hline$\cdot 1 \cdot 0$ &.$- / \cdot 4$ & .1 .9 &.$- / . r$ & & & محبوبيت در ميان دوستان \\
\hline .1 .0 &.$/ \kappa^{4}$ & $.1 \cdot 0$ & $\cdot / \Delta \Lambda^{* * * *}$ & & & فشار اجتماعى براى مصرف مواد مخدر \\
\hline$\cdot 1 \cdot 1$ & $-\cdot / 1 f^{\text {w w }}$ & & & & & فشار اجتماعى × آينده كرايى \\
\hline .1 .9 & $\cdot /\left.1\right|^{c * \omega *}$ & & & & & فشار اجتماعى × جنسيت \\
\hline$\cdot / \cdot v$ & 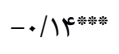 & & & & & فشار اجتماعى × خودكارآمدى \\
\hline$\cdot 1 \cdot \mathrm{r}^{\mathrm{r}}$ &.$- / 11^{*}$ & & & & & فشار اجتماعى × ادراى اخلاقمندى \\
\hline $.1 \cdot 1$ & $-.1 .9 *$ & & & & & فشار اجتماعى × حال كرايى تقديرنغر \\
\hline $.1 \cdot 0$ & &.$|\mu|$ & & .11 & & Rغيير مجذور R \\
\hline
\end{tabular}

\begin{tabular}{|c|c|c|c|c|}
\hline \multicolumn{4}{|c|}{ متغير تعديلگر رابطهى فشار اجتماعى و گرايش به مواد مخدر } & \multirow[b]{2}{*}{ سطح متغير تعديلگر } \\
\hline حال كرايى تقديرنغر & آيندهرًايى & ادراى اخلاقمندى & خودكار آمدى & \\
\hline$\cdot / \Gamma \omega^{\text {半 }}$ & $\cdot /$ 橉 & 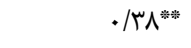 & $\cdot /\left.\mu\right|^{* * *}$ & يك انحراف استاندارد بالاتر از ميانگين \\
\hline$\cdot /\left.\right|^{4}$ & 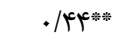 & $\cdot / K \uparrow^{4}$ & $\cdot / 4 \varphi^{4}$ & 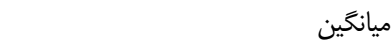 \\
\hline 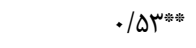 & $\cdot / \Delta Q^{* * *}$ & $\cdot / 0 \cdot * * *$ & $\cdot / \Delta V^{* * *}$ & يك انحراف استاندارد پايينتر از ميانگين \\
\hline
\end{tabular}

به رفتارهاى برخطر بود. در ادامهى يافتههاى يزوهش حاضر، دين بودارى، زندگى والدين

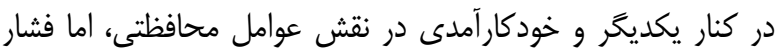

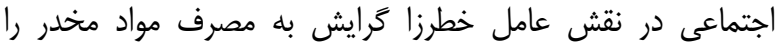

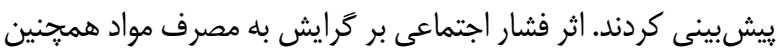
توسط جنسيت، ادراى از اخلاقمندى خود، خودكارآمدى، آيندهرًائى

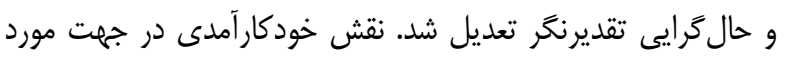

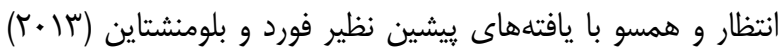
بود. در هر دو مدل، اين عوامل نزديك به نيمى از واريانس كرايش دانشجويان به سيخار كشيدن و مصرف مواد مخدر را تبيين كردند.

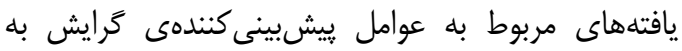

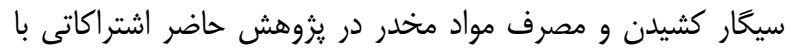

بود. عواملى كه در يثوهش حاضر مدنظر قرار گرفتند عبارت از

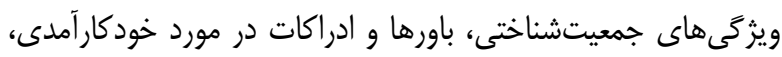

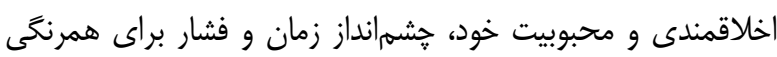

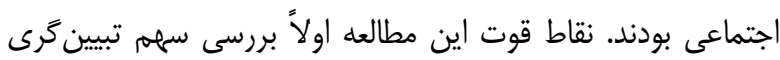

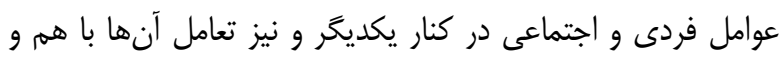

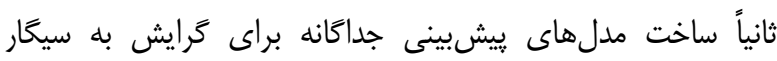
كشيدن و مصرف مواد مخدر بود. بنابر يافتهها، ديندارى و محبوبيت در خانواده در نقش عوامل مول

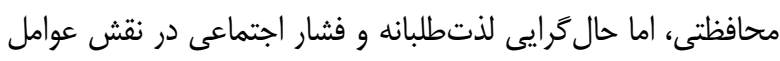

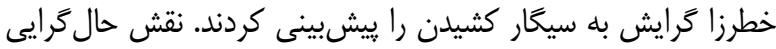

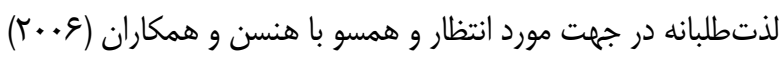

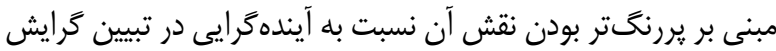


سومين اشتراك بين بيشبينهاى كرايش به سيخار كشيدن

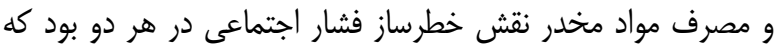

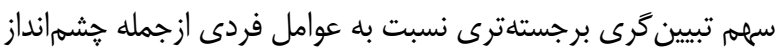

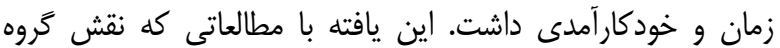

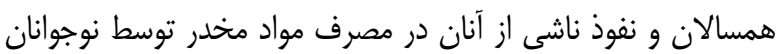
و جوانان را كزارش دادهاند همسو است (مانند بروك و و همكاران،

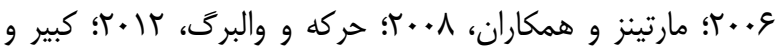

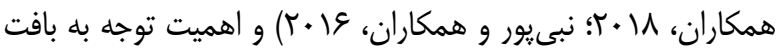

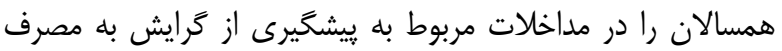

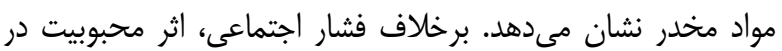

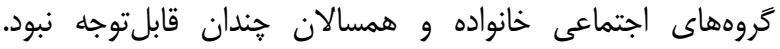
محبوبيت در ميان دوستان كرايش به سيكار كشيدن يا مصرف موناد

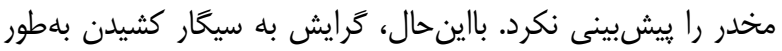

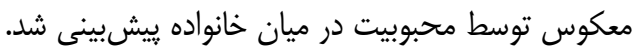
يافتهى مربوط به نقش محافظتى محبوبيت در ميان خانواده

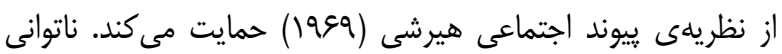

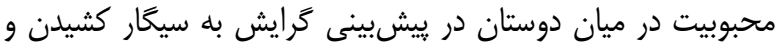

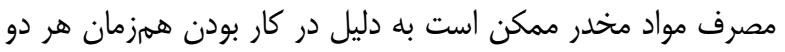

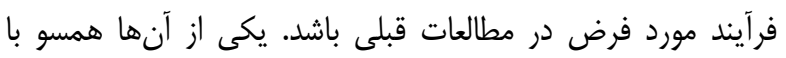

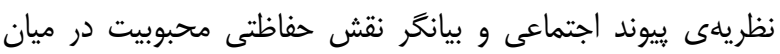

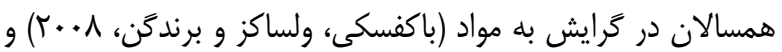
ديخرى مبتنى بر نقش آسيبزاى آن است كه بر اساس آنه، مصرف

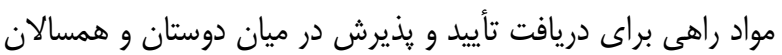

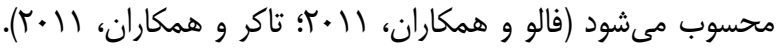

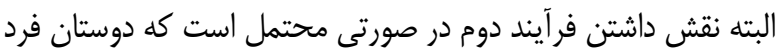

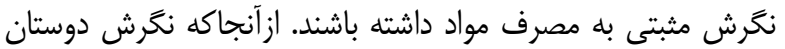

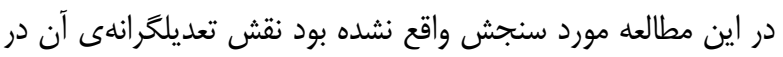
رابطهى بين محبوبيت در ميان دوستان و گرايش به مصرف مواد قابل برابل

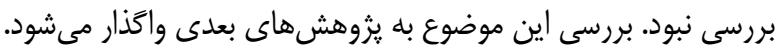

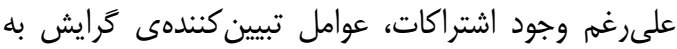
سيكار كشيدن و مصرف مواد مخدر تفاوتهايى نيز با يكديكر داشتند كه اين مطلب ارزش مطالعهى جداكانهى عوامل خطرساز محافظت كنندهى وسوسه نسبت به اين دو را مىنماياند. براى نمونه، در ييشبينى كرايش به سيكار كشيدن קشهمانداز زمان، اما در

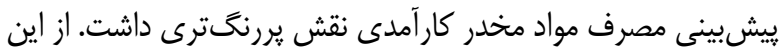

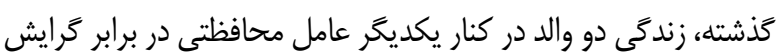

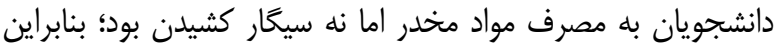
به نظر مىرسد مصرف مواد مخدر بيشتر از سيكار كشيدن با تغييرات ساختارى آسيبزا در خانواده مرتبط باشد.

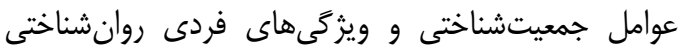
علاوه بر ييشيينى مستقيم كرايش به مصرف مواد مخدر، اثر فشار
يكديخر داشتند. يكى از اين اشتراكات نقش محافظتى ديندارى در

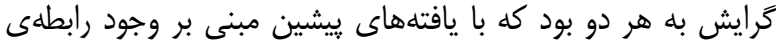

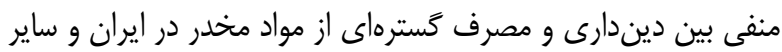

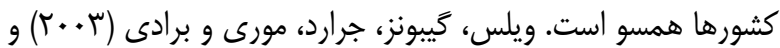

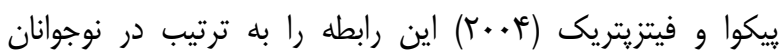
افريقايى-امريكايى و مجارستانى كزارش دادند. مطالعات انجامشده روى كروههاى متنوعى از دانشجوئانيان ايرانى حكايت از وجود رابطهى معكوس بين ديندارى با قليان كشيدان

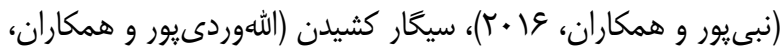

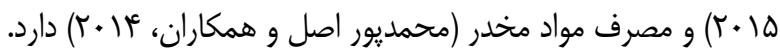

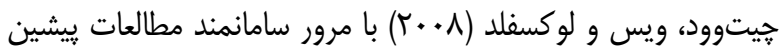
رابطهى بين ديندارى و كاهش خطر مصرف مواد را قابل اطمينان

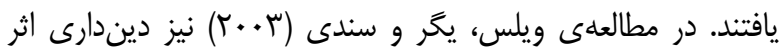
تنشهاى زندگى بر سطح اوليهى مصرف مواد و نرخ رشد مصرف آن در طول زمان را كاهش داد.

بلهنوان دومين اشتراك بين ييشبينهاى كرايش به سيخار

كشيدن و مصرف مواد مخدر، جنسيت در كام اوليهى هر دو مدل

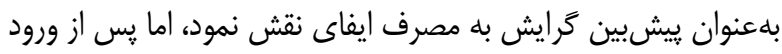

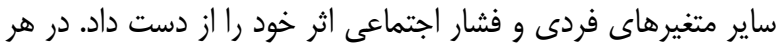

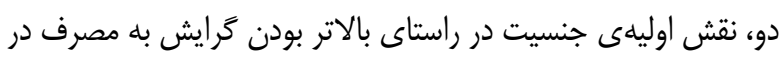
ميان קِران نسبت به دختران و همسو با مطالعات يِيشين (نظير

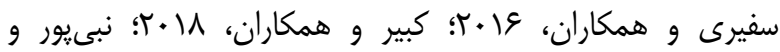

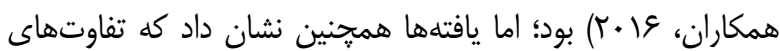
دو جنس در كرايش به سيكار كشيدن و مصرف مواد مخدر عمدتاً

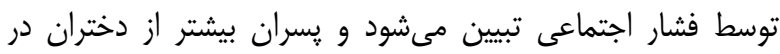

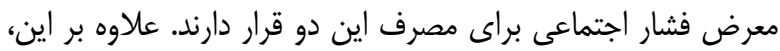
اختلاف بين فشار اجتماعى براى سيخار كشيدن و براى مصرف مورف مواد

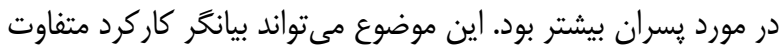

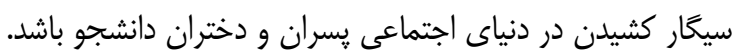

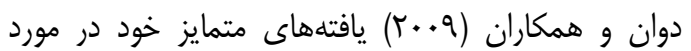

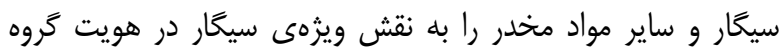

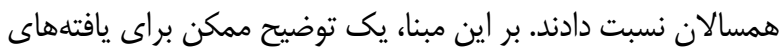

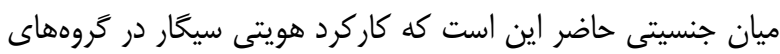

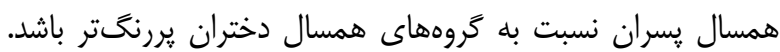
اين موضوع اهميت توجه به عوامل اجتماعى در كرايش به به سيكار كشيدن بخصوص در مورد بسران را مى منماياند. جنسيت تعديل فشار اجتماعى بر كرايش به مصرف مواد مخدر نيز بود، بهوَّونهاى كه

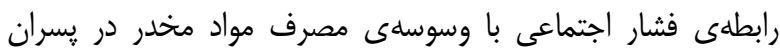

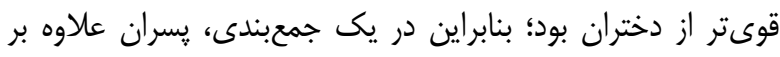
اينكه در معرض فشار بيشترى براى مصرف مواد إز إن سوى همسالانشان قرار دارند، به ميزان بيشترى نيز از آن تأثير مى يذيرند. 
ادراك از اخلاقمندى خود متغيرى فردى بود كه بلقصد

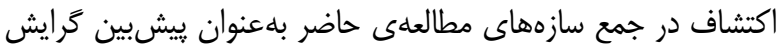
به سيكار كشيدن و مصرف مواد مخدر قرار داده شده بود، اما يافتهها

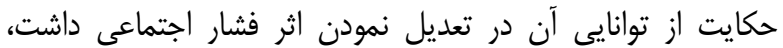

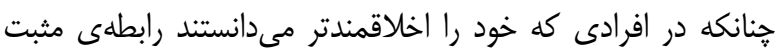
بين فشار اجتماعى و گرايش به مصرف مواد مخدر ضعيفتر بود. شايد بتوان كفت اخلاقى بودن در خوديندارهى افرادى كه خود را اخلاقمندتر

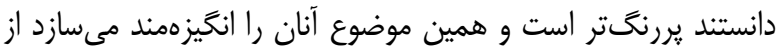
رفتارهايى كه اخلاقى بودنشان را زير سؤال مىبرد، ازجمله سيعار

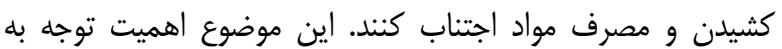
هويت اخلاقى در مطالعات آتى در حوزهى روانشناسى اعتياد را نشان

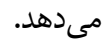

براى اين يزوهش مى توان محدوديتهايى را در نظر گرفت. ازجمله محدوديتهاى يزوهش حاضر مربوط به گروه نمونه است كه يه

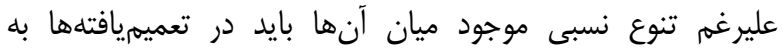

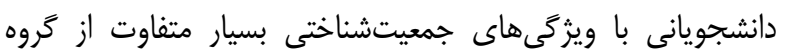
حاضر احتياط كرد. محدوديت دوم عدم تفكيك مواد مخدر از يكديخر

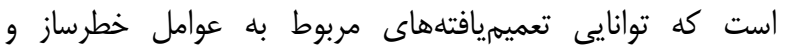

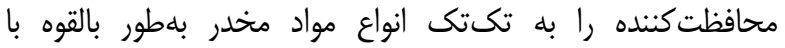

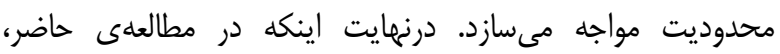

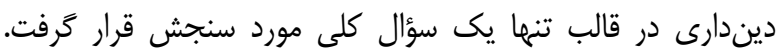

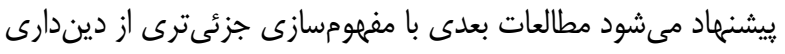

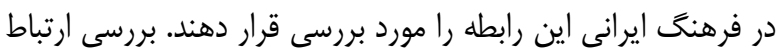

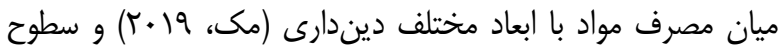
فردى و بافتى ديندارى (والس، ياماگوجى، باخمن، اومالى، شولنبرگ

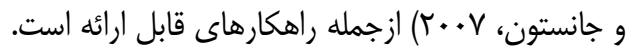

اجتماعى بر آن را نيز تعديل كردند؛ بنابراين، درصورتى كه كاهش يا

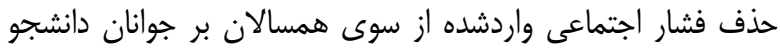

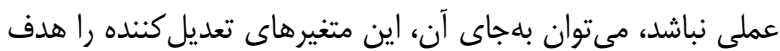

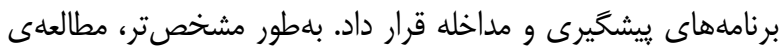

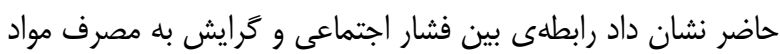

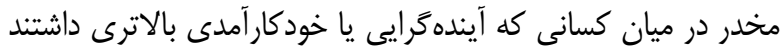

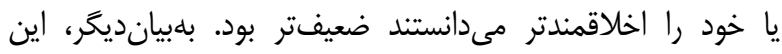
متغيرهاى فردى بلهعنوان عوامل محافظتى در مقابل فشار اجتماعى مئى عمل مى كنند.

يك يافتهى غيرمنتظره، ضعيفتر بودن رابطهى بين فشار

اجتماعى و وسوسهى مصرف مواد مخدر همجنين در ميان كسانى بود كه حال

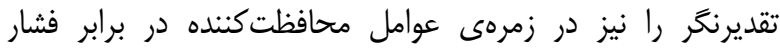

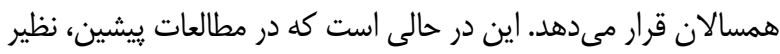

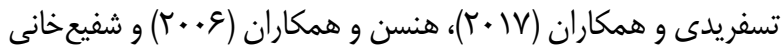

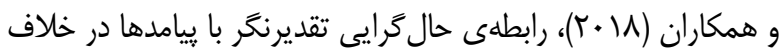
جهت رابطهى آينده گرايى و خودكارآمدى با اين ييامدها بود. در نخاهى

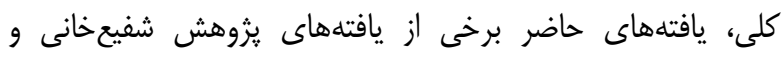

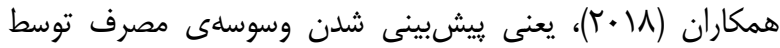

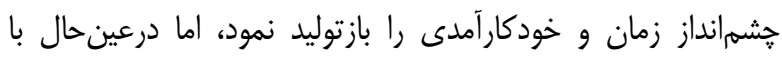

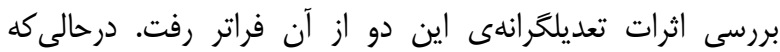
آيندهر ايى و حال گرايى تقديرنگر در مطالعهى شفيع خانى و همكاران

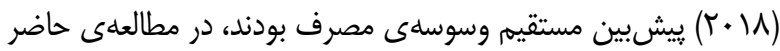
بdعنوان عوامل محافظت كنندهى فرد در برابر فشار اجتماعى براى

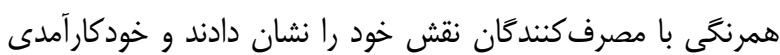
نيز نقش محافظتى دوكانهاى را ايفا نمود.

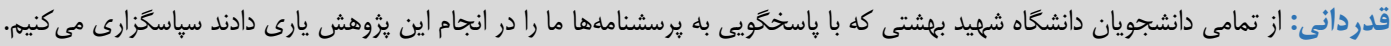

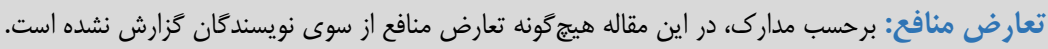
حامى مالى: اين يزوهش بدون حمايت مالى انجام شده است.

\section{References}

Aiken, L. S., \& West, S. G. (1991). Multiple Regression: Testing and interpreting interactions. Newbury Park, CA: Sage.

Allahverdipour, H., Abbasi-Ghahramanloo, A., Mohammadpoorasl, A., \& Nowzari, P. (2015). Cigarette Smoking and its Relationship with Perceived Familial Support and Religiosity of University Students in Tabriz, Iran J Psychiatry, 10 (3), 136-143.

Asch, S. E. (1956). Studies of independence and conformity: I. A minority of one against a unanimous majority. Psychological Monographs, 70, 1-70. [DOI:10.1037/h0093718]
Bandura, A. (1991). Social Cognitive Theory of SelfRegulation. Organizational Behavior and Human Decision Processes, 50 (2), 248-287. [DOI:10.1016/0749-5978(91)90022-L]

Brook, J. S., Pahl, T., Morojele, N. K., \& Brook, D. W. (2006). Predictors of Drug Use among South African Adolescents. J Adolesc Health, 38 (1), 2634. [DOI: 10. 1016/ j. jadohealth. 2004. 08. 004] [PMid:16387245 PMCid:PMC1592364]

Bukowski, W. M., Velsaquez, A. M., \& Brendgen, M. (2008). Variations in patterns of peer influence: Considerations of self and other (pp. 125-140). In M. J. Prinstein \& K. A. Dodge (Eds.), 
Understanding peer influence in children and adolescents. New York: Guilford.

Cambron, C., Catalano, R. F., \& Hawkins, J. D. (2019). The social development model. The Oxford handbook of developmental and life-course criminology, 191, 223-247. [DOI:10.1093/oxford $\mathrm{hb} / 9780190201371.013 .13]$

Chen, C. Y. (2018). Smartphone addiction: psychological and social factors predict the use and abuse of a social mobile application. Information, Communication \& Society, 23 (3), 114. [DOI:10.1080/1369118X. 2018.1518469]

Chen, G., Gully, S. M., \& Eden, D. (2001). Validation of a new general self-efficacy scale. Organizational Research Methods, 4 (1), 62- 83. [DOI:10.1177/109442810141004]

Chitwood, D. D., Weiss, M. L., \& Leukefeld, C. G. (2008). A Systematic Review of Recent Literature on Religiosity and Substance Use. Journal of Drug Issues, 38 (3), 653-688. [DOI:10.1177/0022042 60803800302]

Cohen, G. L., \& Prinstein, M. J. (2006). Peer contagion of aggression and health risk behavior among adolescent males: an experimental investigation of effects on public conduct and private attitudes. Child Development, 77 (4), 967-83. [DOI: 10.1111 / j.1467 - 8624. 2006. 00913. x] [PMid: 16942500]

Duan, L., Chou, C. P., Andreeva, V. A., \& Pentz, M. A. (2009). Trajectories of Peer Social Influences as Long-term Predictors of Drug Use from Early Through Late Adolescence. Journal of Youth and Adolescence, 38, 454-465. [DOI:10.1007/s10964008-9310-y] [PMid:19636757]

Fallu, J. S., Brière, F., Vitaro, F., Cantin, S., \& Borge, A. (2011) The Influence of Close Friends on Adolescent Substance Use: Does Popularity Matter? In: Ittel A., Merkens H., and Stecher L. (Eds) Jahrbuch Jugendforschung. [DOI:10.1007/ 978-3-531-93116-6_9]

Ford, J. A., \& Blumenstein, L. (2013). Self-Control and Substance Use among College Students. Journal of Personality and Social Psychology, 43 (1), 56- 68. [DOI:10.1177/0022042612462216]

Harakeh, Z., \& Vollebergh, W. A. M. (2012). The impact of active and passive peer influence on young adult smoking: An experimental study. Drug and Alcohol Dependence, 121, 220- 223. [DOI:10.1016/j.drugalcdep.2011.08.029] [PMid:21955363]

Hawkins, J. D., \& Weis, J. G. (1985). The social development model: An integrated approach to delinquency prevention. Journal of Primary Prevention, 6, 73- 97. [DOI:10.1007/BF013254 32] [PMid:24271382]

Henson, J. M., Carey, M. P., Carey, K. B., \& Maisto, S. A. (2006). Associations among Health Behaviors and Time Perspective in Young Adults: Model Testing with Boot-Strapping Replication. J Behav Med, 29 (2), 127-137. [DOI:10.1007/s10865-0059027-2] [PMid:16421652 PMCid:PMC2435266]

Hirschi, T. (1969). Causes of delinquency. Berkeley: University of California Press.

Iranpour, A., Jamshidi, E., Nakhaee, N., Haghdoost, A.
A., Shojaeizadeh, D., Eftekhar-Ardabili, M., \& Eftekhar-Ardabili, H. (2015). Development and Psychometric Properties of Risk and Protective Factors of Substance Use Scale in Iran: An Application of Social Development Model. Addiction and Health, 7 (3-4), 117-29.

Jones, T. M., Hill, K. G., Epstein, M., Lee, J. O., Hawkins, J. D., \& Catalano, R. F. (2016). Understanding the interplay of individual and social-developmental factors in the progression of substance use and mental health from childhood to adulthood. Development and psychopathology, 28 (3), 721-741. [DOI:10.1017/S09545794160002 74] [PMid:27427802 PMCid:PMC5011437]

Kabir, K., Bahari, A., Hajizadeh, M., Allahverdipour, H., Tarrahi, M. J., Fakhari, A., Ansari, H., \& Mohammadpoorasl, A. (2018). Substance abuse behaviors among university freshmen in Iran: a latent class analysis. Epidemiol Health, 40. [DOI:10.4178/epih.e2018030] [PMid:30056643 PMCid:PMC6178368]

Kadden, R. M., \& Litt, M. D. (2011). The Role of SelfEfficacy in the Treatment of Substance Use Disorders. Addictive Behaviors, 36 (12), 11201126. [DOI: 10. 1016 / j. addbeh. 2011. 07. 032] [PMid:21849232 PMCid:PMC3179802]

Keough, K. A., Zimbardo, P. G., \& Boyd, J. N. (1999). Who's Smoking, Drinking, and Using Drugs? Time Perspective as a Predictor of Substance Use. Basic and Applied Social Psychology, 21 (2), 149164. [DOI:10.1207/S15324834BA210207]

Kooij, D. T., Kanfer, R., Betts, M., \& Rudolph, C. W. (2018). Future time perspective: A systematic review and meta-analysis. Journal of Applied Psychology, 103 (8), 867. [DOI:10.1037/ap1000 0306] [PMid:29683685]

Mak, H. W. (2019). Dimensions of Religiosity: The Effects of Attendance at Religious Services and Religious Faith on Discontinuity in Substance Use. Journal of studies on alcohol and drugs, 80 (3), 358-365. [DOI:10.15288/jsad.2019.80.358]

Marlatt, G. A., Baer, J. S., \& Quigley, L. A. (1995). Selfefficacy and addictive Behavior (pp. 289-315). In A. Bandura (Ed.), Self-efficacy in Changing Societies. Cambridge University Press. [DOI: 10.1017/CBO9780511527692.012]

Martins, S. S., Storr, C. L., Alexandre, P. K., \& Chilcoat, H. D. (2008). Adolescent Ecstasy and other drug use in the National Survey of Parents and Youth: the role of sensation-seeking, parental monitoring and peer's drug use. Addictive Beahviors, 33 (7), 919-933. [DOI:10.1016/ j.addbeh.2008.02.010] [PMid:18355973 PMCid: PMC2441866]

Mello, Z. R., Oladipo, S. E., Paoloni, V. C., \& Worrell, F. C. (2019). Time perspective and risky behaviors among Nigerian young adults. Journal of Adult Development, 26 (3), 161-171. [DOI:10.1007/ s10804-018-9304-2]

Mohammadpoorasl, A., Ghahramanloo, A. A., Allahverdipour, H., \& Augner, C. (2014). Substance abuse in relation to religiosity and familial support in Iranian college students. Asian journal of psychiatry, 9, 41-44. 
Nabipour, A. R., Alizadeh, A., Hosseini, M. S., Mansouri, Z., Shamsoddini, L., \& Nakhaee, N. (2016). Correlates of water pipe smoking among Iranian university students and the role of religiosity. Int J Psychiatry Med, 51(6), 494-507. [DOI:10.1177/0091217417696735] [PMid:28629297]

Pikoa, B. F., \& Fitzpatrickb, K. M. (2004). Substance use, religiosity, and other protective factors among Hungarian adolescents. Addictive Behaviors, 29 (6), 1095-1107. [DOI:10.1016/j.addbeh.2004.03. 022] [PMid:15236810]

Safiri, S., Rahimi-Movaghar, A., Yunesian, M., Sadeghi-Bazargani, H., Shamsipour, M., Mansournia, M. A., \& Fotouhi, A. (2016). Subgrouping of risky behaviors among Iranian college students: a latent class analysis. Neuropsychiatric Disease and Treatment, 12, 1809-1816. [DOI: 10. 2147 / NDT. S107349] [PMid:27524898 PMCid:PMC4966499]

Shafikhani, M. (2016). The relationship between general self-efficacy and temptation for substance use among adolescents: The mediating role of time perspective and personality traits [Unpublished master's thesis]. Shahid Beheshti University. [In Persian, 1394]

Shafikhani, M., Bagherian, F., \& Shokri, O. (2018). The Mediating Role of Time Perspective in the Relationship between General Self-Efficacy and the Tendency toward Substance Abuse in Female Adolescents. International Journal of Psychology, 12 (1), 208-231. [DOI:10.24200/ijpb.2018.58149]

Sherer, M., Maddux, J. E., Mercandante, B., PrenticeDunn, S., Jacobs, B., \& Rogers, R. W. (1982). Self-efficacy scales: construction and validation. Psychological Reports, 51, 663- 671. [DOI:10. 2466/pr0.1982.51.2.663]

Tseferidi, S. I., Griva, F., \& Anagnostopoulos, F. (2017). Time to get happy: associations of time perspective with indicators of well-being.
Psychology, health \& medicine, 22 (5), 618-624. [DOI:10.1080/13548506.2016.1226508] [PMid:27560279]

Tucker, J. S., Green, H. D., Zhou, A. J., Miles, J. N. V., Shih, R. A., \& D'Amico, E. J. (2011). Substance Use among Middle School Students: Associations with Self-Rated and Peer-Nominated Popularity. Journal of Adolescence, 34 (3), 513-519. [DOI:10.1016/j.adolescence.2010.05.016] [PMid:20580420 PMCid:PMC2950876]

Wallace, J. M., Yamaguchi, R, Bachman, J. G., O'Malley, P. M., Schulenberg, J. E., \& Johnston, L. D. (2007). Religiosity and Adolescent Substance Use: The Role of Individual and Contextual Influences. Social Problems, 54 (2), 308-27. [DOI:10.1525/sp.2007.54.2.308]

Wills, T. A., Gibbons, F. X., Gerrard, M., Murry, V. M., \& Brody, G. H. (2003). Family Communication and Religiosity Related to Substance Use and Sexual Behavior in Early Adolescence: A Test for Pathways Through Self-Control and Prototype Perceptions. Psychology of Addictive Behaviors, 17 (4), 312-323. [DOI:10.1037/0893-164X.17. 4.312] [PMid:14640827]

Wills, T. A., Yaeger, A. M., \& Sandy, J. M. (2003). Buffering Effect of Religiosity for Psychology of Addictive Behaviors, 17 (1), 24-31. [DOI:10. 1037/0893-164X.17.1.24] [PMid:12665078]

Young, J. T. N., \& Weerman, F. M. (2013). Delinquency as a Consequence of Misperception: Overestimation of Friends' Delinquent Behavior and Mechanisms of Social Influence. Social $\begin{array}{llll}\text { Problems, } & 60 & \text { (3), } & 334-356 .\end{array}$ [DOI:10.1525/sp.2013.60.3.334]

Zimbardo, P. G., \& Boyd, J. N. (1999). Putting time in perspective: A valid, reliable individualdifferences metric. Journal of Personality and Social Psychology, 77 (6), 1271- 1288. [DOI: 10.1037/0022-3514.77.6.1271] 